\title{
Comparison of Thermodynamic Cycles for Power Production from Low-Temperature Geothermal Heat Sources
}

\author{
Daniël Walraven ${ }^{\mathrm{a}}$, Ben Laenen ${ }^{\mathrm{b}}$, William D'haeseleer ${ }^{\mathrm{a}, *}$ \\ ${ }^{a}$ University of Leuven (KU Leuven) Energy Institute - TME branch (Applied Mechanics and Energy Conversion), \\ Celestijnenlaan 300A box 2421, B-3001 Leuven, Belgium \\ ${ }^{b}$ Flemish Institute of Technological Research (VITO), Boeretang 200, B-2400 Mol, Belgium
}

\begin{abstract}
The performance of different types of organic Rankine cycles (ORC) and of the Kalina cycle is investigated and optimized for low-temperature $\left(100-150^{\circ} \mathrm{C}\right)$ geothermal heat sources. A variety of configurations is worth considering. The ORC's can be subcritical or transcritical and can have one or more pressure levels. Each cycle can be a simple one, have recuperation or turbine bleeding and up to 80 different working fluids can be used. Comparison of these cycles to each other and to an optimized Kalina cycle concludes that the transcritical and multi-pressure subcritical cycles are the best ones. Exergetic plant efficiencies of above $50 \%$ can be achieved when the brine is allowed to cool down as much as possible. A constraint on the brine outlet temperature causes a strong decrease in the mechanical power output of the cycle. Due to the low heat source temperatures, a low condenser temperature and small temperature differences in the heat exchanger are very important.
\end{abstract}

Keywords: Geothermal, binary cycle, ORC, Kalina

\section{Introduction}

Low-temperature $\left(100-150^{\circ} \mathrm{C}\right)$ geothermal heat sources have a very large potential as a renewable energy source $[1,2]$. The amount of energy available is huge, but due to the low-temperature, the electricity conversion efficiency is low. For this energy conversion, the use of flash-steam power plants is difficult [3] and therefore two types of binary cycles are proposed in the literature. The first one is the organic Rankine cycle (ORC), which is similar to a steam Rankine cycle, but uses an organic working fluid instead of water. A second type is the so-called Kalina cycle. The Kalina cycle is similar to an ORC, but uses a mixture of water and ammonia with a variable composition as working fluid $[4,5,6]$. ORC's are used for different low-temperature heat sources (biomass, geothermal, solar, etc.) [7].

Different configurations of ORC's have been proposed in the literature. Subcritical ORC's with or without recuperator are optimized by Dai, Y. and Wang, J. and Gao, L. [8] for 10 different working fluids. It is shown that R236ea is the best performing working fluid for an inlet temperature of $145^{\circ} \mathrm{C}$ and that a recuperator is not always useful. Cayer et al. [9] have optimized a transcritical ORC for a heat-source temperature of $100^{\circ} \mathrm{C}$ and a turbine inlet temperature between 80 and $100^{\circ} \mathrm{C} . \mathrm{CO}_{2}$, ethane and $\mathrm{R} 125$ are used as possible working fluids. Only the simple ORC configuration with a pump, heat exchanger, turbine and condenser are considered. Kanoglu [10] has investigated multi-pressure cycles. An exergy analysis of an existing power plant, which uses the combination of 2 subcritical cycles with isopentane, has been performed. Gnutek and Bryszewska-Mazurek [11] have considered a multi-cycle ORC. The power plant consists of 4

\footnotetext{
Published version: http://dx.doi.org/10.1016/j.enconman.2012.10.003

*Corresponding author. Tel.: +32 163225 11; fax: +32 16322985.

Email addresses: Daniel.Walraven@mech.kuleuven.be (Daniël Walraven), Ben.Laenen@vito.be (Ben Laenen), William.Dhaeseleer@mech.kuleuven.be (William D'haeseleer)
} 
subcritical power cycles, using the heat source in series. Heberle and Brüggemann [12] have concluded that for power generation from low-temperature geothermal heat sources, fluids with a low critical temperature are optimum. Only cycles which use a recuperator have been investigated. Mago et al. [13] have compared simple ORC's with ORC's which use turbine bleeding (called "regenerative" in the paper). It is concluded that the cycle efficiency of the so-called regenerative cycle is higher than that of the simple cycle. It is also stated that reheat ORC's do not perform better than a simple ORC. Different configurations of subcritical ORC's have been compared by Yari [14]. Simple cycles, cycles with recuperation, cycles with turbine bleeding and cycles with recuperation and turbine bleeding are simulated. All these cycles are subcritical ones with a fixed evaporation temperature of $120^{\circ} \mathrm{C}$. It is shown that cycles with recuperation or turbine bleeding are the most promising ones. Subcritical and transcritical cycles with or without recuperation have been investigated by Saleh et al. [15] for many working fluids. For low-temperature geothermal sources, it is shown that fluids with a low critical pressure in the transcritical cycles are optimum. Borsukiewicz-Gozdur, A. and Nowak, W. [16] improved the power output of an ORC by returning a part of the geothermal water after the evaporator to the inlet of the evaporator. The influence of cooling medium temperature, working fluid flow rate, etc. on the performance of ORC's is investigated by Nguyen, TQ and Slawnwhite, JD and Boulama, K.G. [17].

For low-temperature sources, the Kalina is often mentioned as an alternative for the ORC. [4, 5, 6]. Although the Kalina cycle is often called to be superior to the ORC [4, 6], DiPippo [18] has shown that an existing Kalina cycle has about the same performance as existing ORC's.

As seen from the list above, many thermodynamic cycles for low temperature heat sources have been proposed in the literature. In all of the mentioned references, the number of cycle configurations or the number of fluids is limited and often only one heat source inlet temperature is investigated. Often certain asssumptions are made like a fixed evaporation temperature, no superheated cycles, etc. In this paper the most promising of these proposed cycles are simulated, optimized and compared to eachother. So, simple ORC's, recuperated ones and ORC's with turbine bleeding are treated. All of these can have one or more pressure levels and every pressure level can be subcritical or transcritical. Up to 80 fluids are investigated as a working fluid. The Kalina cycle is also simulated, optimized and exergetically compared to the different ORC's. In this way, the thermodynamic optimum binary cycle is found for different brine inlet temperatures, condenser temperatures and pinch point temperature differences. The influence of a constraint on the brine outlet temperature on the cycle configuration and performance is also investigated.

\section{Definition of Different Efficiencies}

In the literature, different definitions for efficiencies exist. All of these efficiencies are useful, but they often have a different meaning. Therefore, it is important to know how the efficiencies are defined and to use the right efficiency at the right moment.

\subsection{Cycle Efficiency}

The cycle efficiency describes how well a thermodynamic cycle converts heat, which is added to the cycle, to mechanical power. The energetic cycle efficiency $\eta_{e n}^{\text {cycle }}$ is defined as the fraction of the net mechanical power output to the heat input:

$$
\eta_{\text {en }}^{\text {cycle }}=\frac{\dot{W}_{\text {net }}}{\dot{Q}_{i n}}
$$

$\dot{W}_{n e t}$ and $\dot{Q}_{i n}$ are the net mechanical power output and the heat input to the cycle, respectively. When the heat source is a geothermal brine, the heat added to the cycle can be written as

$$
\dot{Q}_{\text {in }}=\dot{m}_{\text {brine }} \Delta h_{\text {brine }}=\dot{m}_{\text {brine }}\left(h_{\text {in }}-h_{\text {out }}\right)
$$

with $\dot{m}_{\text {brine }}$ the mass flow of brine, $\Delta h_{\text {brine }}$ the specific enthalpy drop of the brine, $h_{\text {in }}$ and $h_{\text {out }}$ the specific enthalpy of the brine before and after heat is added to the cycle. 
Analogous to the energetic cycle efficiency, also an exergetic cycle efficiency $\eta_{e x}^{c y c l e}$ can be defined:

$$
\eta_{\text {ex }}^{\text {cycle }}=\frac{\dot{W}_{\text {net }}}{\dot{m}_{\text {brine }}\left(e_{\text {in }}-e_{\text {out }}\right)}
$$

where $e_{\text {in }}$ and $e_{\text {out }}$ are the specific flow exergy of the brine before and after heat is added to the cycle, respectively. The specific flow exergy $e$ is defined as:

$$
e=\left(h-h_{0}\right)-T_{0}\left(s-s_{0}\right),
$$

where $s$ is the specific entropy of the brine and the subscript 0 refers to the dead state; so $T_{0}$ is the dead-state temperature, usually being the temperature of the environment.

\subsection{Plant Efficiency}

The cycle efficiency of the previous section only describes how efficient a cycle is in converting a certain amount of heat into mechanical power, but it does not tell how efficient the heat source is used. Therefore, both energetic $\eta_{e n}^{p l a n t}$ and exergetic $\eta_{e x}^{p l a n t}$ plant efficiencies are defined, respectively:

$$
\begin{aligned}
\eta_{\text {en }}^{\text {plant }} & =\frac{\dot{W}_{\text {net }}}{\dot{Q}_{\text {available }}}=\frac{\dot{W}_{\text {net }}}{\dot{m}_{\text {brine }}\left(h_{\text {in }}-h_{0}\right)} \\
\eta_{\text {ex }}^{\text {plant }} & =\frac{\dot{W}_{\text {net }}}{\dot{E}_{\text {available }}}=\frac{\dot{W}_{\text {net }}}{\dot{m}_{\text {brine }} e_{\text {in }}}
\end{aligned}
$$

$\dot{Q}_{\text {available }}$ and $\dot{E}_{\text {available }}$ are the heat and exergy in the heat source, respectively. These plant efficiencies can be rewritten in function of the respective cycle efficiencies:

$$
\begin{aligned}
\eta_{\text {en }}^{\text {plant }} & =\frac{\dot{W}_{\text {net }}}{\dot{m}_{\text {brine }}\left(h_{\text {in }}-h_{\text {out }}\right)} \frac{\dot{m}_{\text {brine }}\left(h_{\text {in }}-h_{\text {out }}\right)}{\dot{m}_{\text {brine }}\left(h_{\text {in }}-h_{0}\right)} \\
& =\eta_{\text {en }}^{\text {cycle }} \eta_{\text {en }}^{\text {cooling }} \\
\eta_{\text {ex }}^{\text {plant }} & =\frac{\dot{W}_{\text {net }}}{\dot{m}_{\text {brine }}\left(e_{\text {in }}-e_{\text {out }}\right)} \frac{\dot{m}_{\text {brine }}\left(e_{\text {in }}-e_{\text {out }}\right)}{\dot{m}_{\text {brine }} e_{\text {in }}} \\
& =\eta_{\text {ex }}^{\text {cycle }} \eta_{\text {ex }}^{\text {cooling }}
\end{aligned}
$$

where $\eta_{e n}^{\text {cooling }}$ and $\eta_{e x}^{\text {cooling }}$ show how efficient the geothermal brine is cooled in the energetic and exergetic sense, respectively.

When a geothermal brine is used to produce electricity, the goal is to maximize the net work output per mass unit of brine. So, the fraction $\dot{W}_{n e t} / \dot{m}_{\text {brine }}$ should be maximized. As seen from Eqs. (5) and (6) this is the same as maximizing the energetic or exergetic plant efficiency, because $h_{i n}, h_{0}$ and $e_{i n}$ only depend on the geothermal source and the environment.

Equations (8) and (11) show that the heat source should be cooled down as far as possible (i.e., $\eta_{i}^{\text {cooling }} \rightarrow$ 1) and the heat added to the cycle should be efficiently converted to electricity, to have a high plant efficiency and thus a high power output per mass unit of brine.

In this paper, different configurations of Organic Rankine Cycles (ORC's) and the Kalina cycle will be described and optimized for maximum plant efficiency.

\section{Organic Rankine Cycle}

In this section, different types of ORC's are described. 


\subsection{Subcritical and Transcritical ORC's}

A distinction has to be made between subcritical, transcritical and supercritical cycles. In a subcritical cycle, the pressure is always below the critical pressure and in a supercritical cycle, the pressure is always above the critical pressure. In a transcritical cycle, the low pressure is below the critical pressure, and the high pressure above the critical one ${ }^{1}$. In this paper, only subcritical and transcritical cycles are investigated.

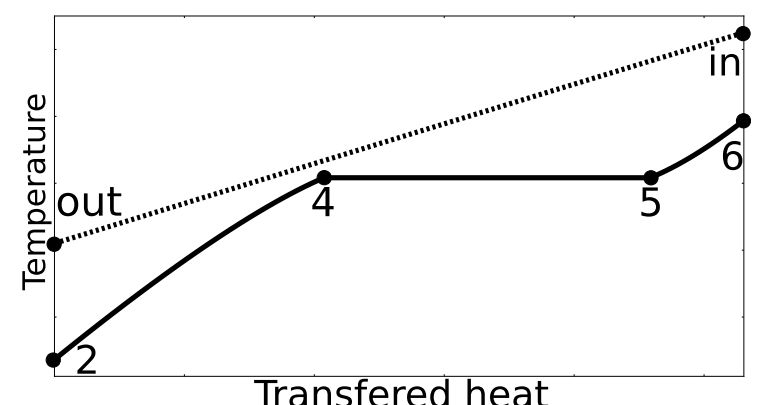

(a) Subcritical

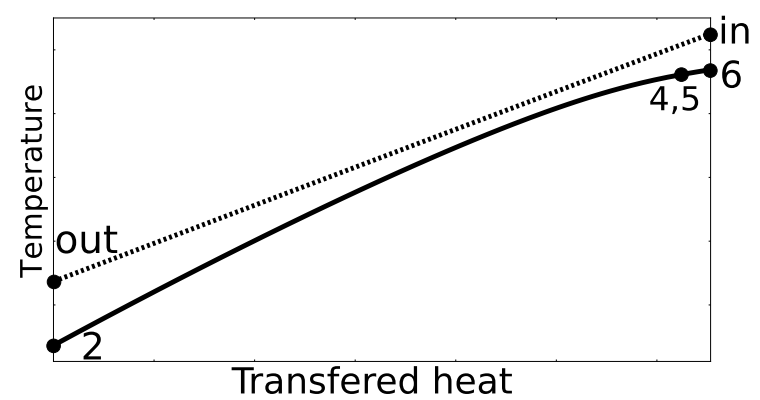

(b) Transcritical

Figure 1: Temperature-heat diagrams of the heating process in a subcritical (a) and transcritical (b) cycle. The working fluid $(-)$ is heated by the cooling brine $(\cdots)$.

Figure 1 shows the temperature-heat diagram of the heating process in a subcritical and a transcritical cycle. In the subcritical cycle, the working fluid is heated in the economizer $(2 \rightarrow 4)$, in the evaporator $(4 \rightarrow 5)$ and in the superheater $(5 \rightarrow 6)$. Due to the evaporation at constant temperature in the subcritical cycle, large temperature differences between the brine cooling curve and the working fluid heating curve exist. These temperature differences induce the creation of high irreversibilities. In the transcritical cycle, the temperature differences between the brine cooling curve and the working fluid heating curve are smaller. So, the irreversibilities created during the heat exchange of the transcritical case are smaller and because of the better fit between the curves, the brine can cool down more than in the subcritical case.

\subsection{ORC Configurations}

Three ORC configurations are investigated, as shown in figure 2. These three configurations can be subcritical or transcritical, depending on the maximum pressure in the cycle. In the simple ORC (figure 2a), the working fluid is pumped from the low to the high pressure $(1 \rightarrow 2)$, heated by the brine $(2 \rightarrow 6)$, expanded in the turbine $(6 \rightarrow 7)$ and cooled in the condenser $(7 \rightarrow 1)$. Often, state 7 is still at a high temperature and a recuperator can be used as shown in figure $2 \mathrm{~b}$. This configuration will improve the cycle efficiency, because less heat is needed for the same power output. Another method to improve the cycle efficiency is the use of turbine bleeding as depicted in figure 2c. Part of the working fluid (state 8) is extracted from the turbine at an intermediate pressure and is mixed with state 2 to form state 9 . Then the working fluid is pumped to the high pressure $(9 \rightarrow 3)$ and the rest of the cycle is analogous to the simple ORC.

\subsection{Number of Pressure Levels}

The cycles shown in figure 2 have only one high pressure level (except for the steam-bleeding case, which has an intermediate bleeding pressure). It is possible to combine two or more of these cycles. Figure 3a shows a simple ORC with three pressure levels, but other configurations are also possible. The brine, which is not shown on the figure, is split into parts to heat the different cycles. This splitting is done in such a way that the hot brine first heats the working fluid at the highest temperature. Figure $3 \mathrm{~b}$ shows the temperature-heat diagram of a three-pressure level, subcritical cycle without superheating. The three sub-cycles are called $a$, $b$ and $c$ and $p_{a}<p_{b}<p_{c}$. It is seen that the temperature difference between the brine cooling curve and the working fluid heating curve is lower than for a subcritical cycle with one pressure level. So, efficiency improvements can be obtained by applying more than one pressure level.

\footnotetext{
${ }^{1}$ The so-called "supercritical steam cycle" is actually a transcritical cycle according to this definition.
} 


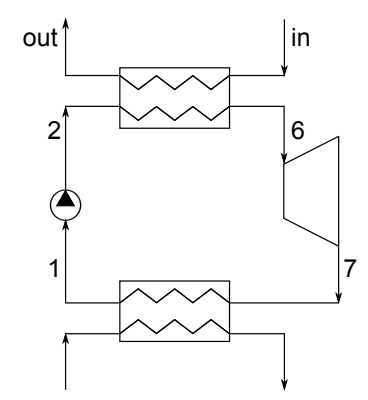

(a) Simple ORC

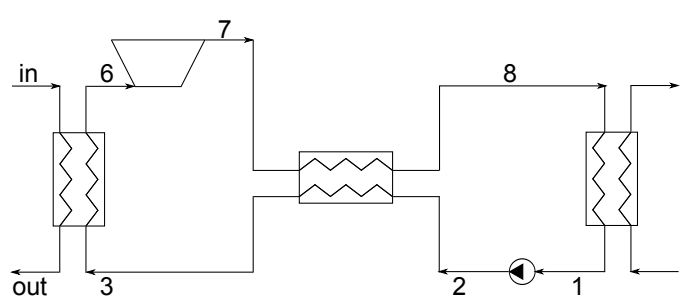

(b) ORC with recuperation

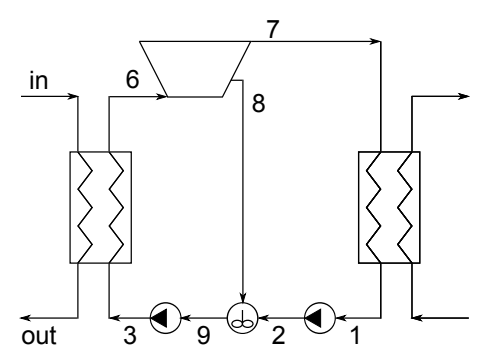

(c) ORC with turbine bleeding

Figure 2: Different ORC configurations: simple ORC (a), ORC with recuperator (b) and ORC with turbine bleeding (c). The brine in- and outlet are given by "in" and "out", respectively.

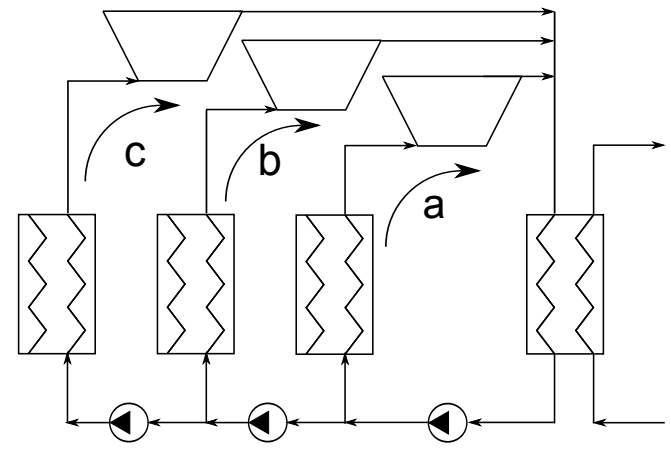

(a) Triple-pressure simple ORC

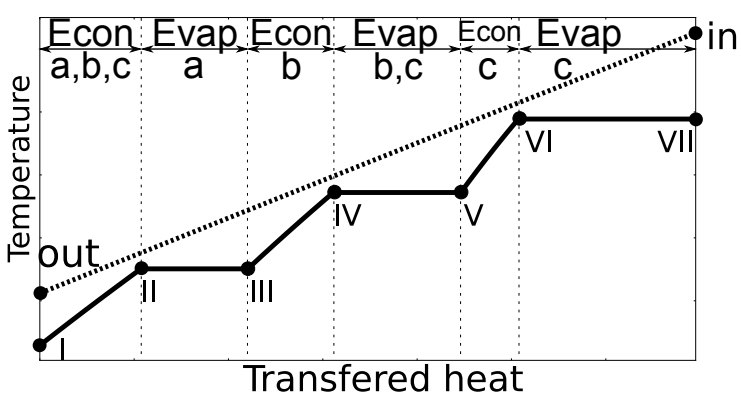

(b) Temperature-heat diagram

Figure 3: Scheme and temperature-heat diagram of a triple-pressure,subcritical cycle without superheating. The working fluid $(-)$ is heated by the cooling brine $(\cdots)$. The three pressure levels are called $a, b$ and $c$. The economizers and evaporators are denoted by "Econ" and "Evap", respectively.

\subsection{Modeling of the ORC's}

For the modeling of the ORC's, it is assumed that the condenser temperature $T_{\text {cond }}$, the isentropic pump efficiency $\eta_{P}$ and isentropic turbine efficiency $\eta_{T}$ are known. Further assumptions are that state 1 is saturated liquid and that the heat exchangers are ideal (no pressure drop and heat loss). It is allowed that the working fluid at the inlet of the turbine (state 6) is superheated for all types of fluids (even for the so-called dry ${ }^{2}$ ones).

For the cycle with recuperation, it is assumed that as much heat as possible is recuperated, taking into account a minimum temperature difference in the recuperator $\Delta T_{\min }^{\text {recup }}$. For the cycle with turbine bleeding, it is assumed that state 9 is saturated liquid. The mass flow at the inlet of the turbine is given by $\dot{m}_{w f}$. The fraction $\varepsilon$ is extracted at the intermediate pressure and the other part (1- $\varepsilon$ ) expands to the condenser pressure.

\subsubsection{Pump and Turbine}

The relationship between the states before (state 1) and after (state 2) the pump are given by:

$$
h_{2}=h_{1}+\frac{h_{2 s}-h_{1}}{\eta_{P}}
$$

with state 1 at the low pressure $p_{\text {low }}$, state 2 at the high pressure $p_{\text {high }}$ and state $2 \mathrm{~s}$ at $p_{\text {high }}$ and the same entropy as state 1 . The mechanical power needed to drive the pump $\dot{W}_{P}$ is:

$$
\dot{W}_{P}=\dot{m}_{w f}\left(h_{2}-h_{1}\right)
$$

\footnotetext{
${ }^{2} \mathrm{~A}$ dry fluid has a saturated vapor line with a positive slope in the temperature-entropy diagram.
} 
with $\dot{m}_{w f}$ the mass flow of the working fluid. The irreversibility created in this pump, is:

$$
\begin{aligned}
\dot{I}_{P} & =\left(\dot{m}_{w f} e_{1}+\dot{W}_{P}\right)-\left(\dot{m}_{w f} e_{2}\right) \\
& =\dot{m}_{w f} T_{0}\left(s_{2}-s_{1}\right)
\end{aligned}
$$

For the second pump in the cycle with turbine bleeding, the equations are analogous:

$$
\begin{aligned}
\dot{W}_{P} & =(1-\varepsilon) \dot{m}_{w f}\left(h_{2}-h_{1}\right)+\dot{m}_{w f}\left(h_{3}-h_{9}\right) \\
\dot{I}_{P} & =(1-\varepsilon) \dot{m}_{w f} T_{0}\left(s_{2}-s_{1}\right)+\dot{m}_{w f} T_{0}\left(s_{3}-s_{9}\right)
\end{aligned}
$$

For the turbine, the relationship between the states at the turbine inlet (state 6) and at the turbine outlet (state 7) is given by:

$$
h_{7}=h_{6}-\left(h_{6}-h_{7 s}\right) \eta_{T}
$$

with state 6 at $p_{\text {high }}$, state 7 at $p_{\text {low }}$ and state $7 \mathrm{~s}$ at $p_{\text {low }}$ and the same entropy as state 6 . The turbine mechanical power and irreversibility generated in the turbine are:

$$
\begin{aligned}
\dot{W}_{T} & =\dot{m}_{w f}\left(h_{6}-h_{7}\right) \\
\dot{I}_{T} & =\dot{m}_{w f} T_{0}\left(s_{7}-s_{6}\right)
\end{aligned}
$$

For the cycle with turbine bleeding, these equations are:

$$
\begin{aligned}
\dot{W}_{T} & =\dot{m}_{w f}\left(h_{6}-h_{8}\right)+(1-\varepsilon) \dot{m}_{w f}\left(h_{8}-h_{7}\right) \\
\dot{I}_{T} & =\dot{m}_{w f} T_{0}\left(s_{8}-s_{6}\right)+(1-\varepsilon) \dot{m}_{w f} T_{0}\left(s_{7}-s_{8}\right)
\end{aligned}
$$

In this paper, the net mechanical power output is given by:

$$
\dot{W}_{n e t}=\dot{W}_{T}-\dot{W}_{P}
$$

So, the power needed for cooling and other auxiliary power is not taken into account.

\subsubsection{Heat exchangers}

The heat exchangers are assumed to be ideal; so no pressure drop is induced and no heat is lost to the environment. The energy balance for the heat exchanger $H X$ between the brine and working fluid is given by:

$$
\dot{m}_{\text {brine }}\left(h_{\text {in }}-h_{\text {out }}\right)=\dot{m}_{w f}\left(h_{6}-h_{3}\right)
$$

A fixed pinch point temperature difference $\Delta T_{\min }^{H X}$ is assumed in this heat exchanger. In the recuperator, the energy balance is:

$$
\left(h_{7}-h_{8}\right)=\left(h_{3}-h_{2}\right)
$$

and the minimum temperature difference is given by $\Delta T_{\mathrm{min}}^{\text {recup }}$. The pinch point temperature differences $\Delta T_{\min }^{H X}$ and $\Delta T_{\min }^{r e c u p}$ are generally not the same. The energy equation for the condenser in the simple or recuperated cycle is given by

$$
\dot{m}_{w f}\left(h_{x}-h_{1}\right)=\dot{m}_{\text {cooling }}\left(h_{\text {out }}^{\text {cooling }}-h_{\text {in }}^{\text {cooling }}\right)
$$

with $h_{x}=h_{7}$ in the simple cycle and $h_{x}=h_{8}$ in the cycle with recuperator. The pinch point temperature difference in the condenser is $\Delta T_{\text {min }}^{\text {cond }}$, a mass flow $\dot{m}_{\text {cooling }}$ of cooling water is used and $h_{\text {in }}^{\text {cooling }} \& h_{\text {out }}^{\text {cooling }}$ are the enthalpy of the cooling water before and after the condenser, respectively.

The irreversibilities created in the heat exchanger $H X$ and recuperator are:

$$
\begin{aligned}
\dot{I}_{H X} & =\left(\dot{m}_{\text {brine }} e_{i n}+\dot{m}_{w f} e_{3}\right)-\left(\dot{m}_{\text {brine }} e_{\text {out }}+\dot{m}_{w f} e_{6}\right) \\
& =\dot{m}_{\text {brine }} T_{0}\left(s_{\text {out }}-s_{\text {in }}\right)+\dot{m}_{w f} T_{0}\left(s_{6}-s_{3}\right) \\
\dot{I}_{\text {recup }} & =\dot{m}_{w f}\left[\left(e_{2}+e_{7}\right)-\left(e_{3}+e_{8}\right)\right] \\
& =\dot{m}_{w f} T_{0}\left[\left(s_{3}-s_{2}\right)+\left(s_{8}-s_{7}\right)\right]
\end{aligned}
$$


The irreversibilities created in the cooling installation are given by

$$
\dot{I}_{\text {cooling }}=\dot{m}_{w f}\left(e_{x}-e_{1}\right)
$$

with $e_{x}=e_{7}$ for the simple cycle and $e_{x}=e_{8}$ for the cycle with recuperation. So, in the cooling installation, all the exergy is lost to the environment. For the cycle with turbine bleeding, the irreversibility creation is:

$$
\dot{I}_{c o o l}=(1-\varepsilon) \dot{m}_{w f}\left(e_{7}-e_{1}\right)
$$

\subsubsection{Mixing}

In the cycle with turbine bleeding, two flows are mixed. The energy equation for the mixing process is given by:

$$
\varepsilon h_{8}+(1-\varepsilon) h_{2}=h_{9}
$$

and the irreversibility created is:

$$
\begin{aligned}
\dot{I}_{m i x} & =\dot{m}_{w f}\left(\left[(1-\varepsilon) e_{2}+\varepsilon e_{8}\right]-e_{9}\right) \\
& =\dot{m}_{w f} T_{0}\left(s_{9}-\left[(1-\varepsilon) s_{2}+\varepsilon s_{8}\right]\right)
\end{aligned}
$$

\subsection{Optimization}

As mentioned in section 2, the objective of the optimization is to maximize the plant efficiency. The decision variables for a simple and a recuperated ORC are the pressure and the temperature at the turbine inlet (state 6) of every pressure level. This state can be saturated or superheated vapor. The boundaries for the temperature of state 6 are: $T_{\text {cond }} \leq T_{6} \leq T_{i n}-\Delta T_{\min }^{H X}$ and the pressure should be higher than the condenser pressure. For a cycle with turbine bleeding, the bleeding pressures of every pressure level are added as decision variables. This pressure should be higher than the condenser pressure and lower than the maximum pressure of the cycle. It is also limited from above by the critical pressure of the fluid. In every optimization step, all the states of the cycle can be determined by the value of the decision variables at that moment. The mass flow of working fluid is calculated by equation (23) and by the value of $\Delta T_{\text {min }}^{H X}$.

\section{Kalina Cycle}

The scheme of a typical Kalina cycle, which always contains a recuperator, is shown in figure 4a. State 1 , which has an intermediate concentration of ammonia $x_{i n t}$, is pumped to the high pressure $(1 \rightarrow 2)$, heated in a recuperator $(2 \rightarrow 3)$ and heated by the brine $(3 \rightarrow 5)$. State 5 is in the two-phase region and the vapor part (state 6 with a high concentration of ammonia $x_{\text {high }}$ ) is split from the liquid part (state 9 with a low concentration of ammonia $\left.x_{\text {low }}\right)$ in the separator. State 6 is expanded in the turbine $(6 \rightarrow 7)$, mixed with state $9(7+9 \rightarrow 11)$, cooled in the recuperator $(11 \rightarrow 8)$ and cooled in the condenser $(8 \rightarrow 1)$. Often a second recuperator is used to exchange heat between states 9 and 3, but in this paper this heat exchanger is omitted because the mass flow around the turbine is small.

Figure $4 \mathrm{~b}$ show the corresponding temperature-heat diagram of the Kalina cycle of Fig. 4a. Because a mixture of fluids is used, the evaporation at constant pressure does not take place at a constant temperature. This "temperature glide" decreases the temperature difference in the heat exchange between brine and working fluid; so less irreversibilities are created in the Kalina cycle than in a subcritical ORC. The temperature-glide at the condenser pressure allows a strong internal heat recuperation.

\subsection{Modeling of the Kalina cycle}

The only component which has not yet been described in the section of the ORC's is the separator. In this component, the two-phase fluid is separated into its liquid and vapor part. An amount $\dot{m}_{w f}$ of working fluid is heated in the heat exchanger, the fraction $\varepsilon$ of this mass flow is expanded in the turbine:

$$
\varepsilon=\frac{x_{\text {int }}-x_{\text {low }}}{x_{\text {high }}-x_{\text {low }}}
$$




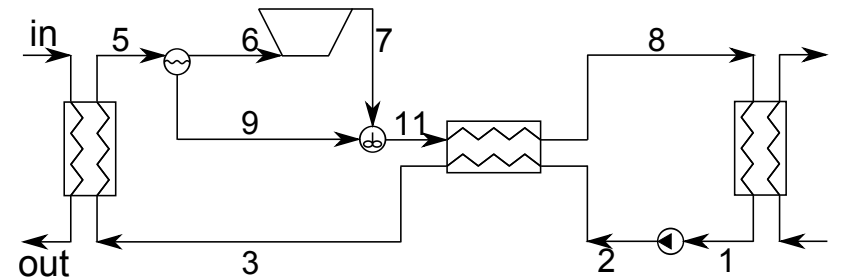

(a) Scheme of the Kalina cycle.

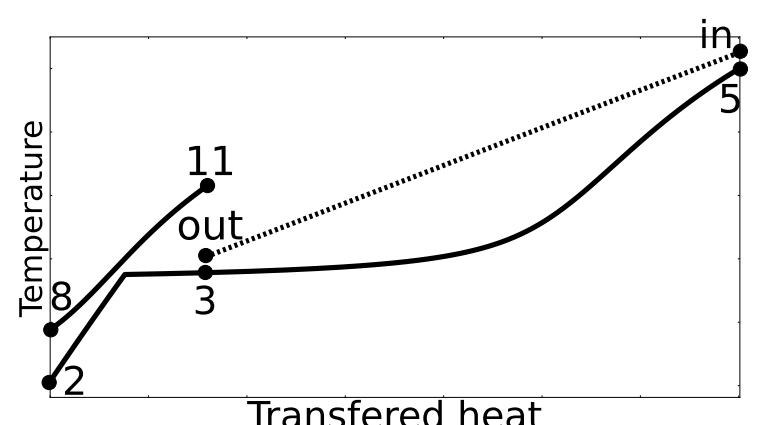

(b) Temperature-heat diagram of the Kalina cycle.

Figure 4: Scheme and temperature-heat diagram of the Kalina cycle. The working fluid $(-)$ is heated by the cooling brine $(\cdots)$.

\subsection{Optimization}

The objective is to maximize the plant efficiency. The decision variables for the Kalina cycle are the temperature and pressure at the turbine inlet (state 6) and the intermediate concentration of ammonia $x_{\text {int }}$. The limits for the temperature and pressure are analogous to the ones for the ORC's. The concentration is limited by: $0<x_{i n t}<0.96$. The upper limit is chosen to avoid numerical problems in the calculation of the fluid properties (section 5.1).

\section{Results and Discussion}

In this section, the results of the comparison between the ORC configurations of Figs. $2 \& 3$ and the Kalina cycle of Fig. 4 for the different cases are given. All the simulations have been performed with our own developed code, written in Python. The thermodynamic properties are obtained from RefProp [19], which is connected to Python by using F2PY [20]. The SLSQP optimization subroutine from Scipy [21] is used as the optimizer.

\subsection{Input Parameters}

Table 1 shows the parameters which are used in the remainder of this paper, unless denoted otherwise. The brine inlet temperature and pressure are given by $T_{i n}$ and $p_{i n}$, respectively. The cooling water temperature is taken equal to $T_{0}$.

\begin{tabular}{|l|l|}
\hline$T_{\text {in }}$ & $125^{\circ} \mathrm{C}$ \\
\hline$p_{\text {in }}$ & $5 \mathrm{bar}$ \\
\hline$T_{\text {cond }}$ & $25^{\circ} \mathrm{C}$ \\
\hline$T_{0}$ & $15^{\circ} \mathrm{C}$ \\
\hline$p_{0}$ & 1 bar \\
\hline
\end{tabular}

\begin{tabular}{|l|c|}
\hline$\eta_{P}$ & $80 \%$ \\
\hline$\eta_{T}$ & $85 \%$ \\
\hline$\Delta T_{\min }^{H X}$ & $5^{\circ} \mathrm{C}$ \\
\hline$\Delta T_{\min }^{\text {recup }}$ & $5^{\circ} \mathrm{C}$ \\
\hline$\Delta T_{\text {min }}^{\text {cond }}$ & $5^{\circ} \mathrm{C}$ \\
\hline
\end{tabular}

Table 1: Input parameters.

For some fluids available in RefProp, only supercritical cycles are possible and they are therefore skipped. All other fluids are used in the calculations to obtain the thermodynamic optimum cycle configuration. Only thermodynamic properties of the fluids are taken into account. Other properties like ozone depletion potential, global warming potential, flammability, etc. are not taken into account. For the Kalina cycle, a maximum ammonia concentration of $96 \%$ is used, because for higher concentrations RefProp is not always able to find the thermodynamic properties of the mixture. 


\begin{tabular}{|lcccccll|}
\hline Working fluid & $T_{6}\left[{ }^{\circ} \mathrm{C}\right]$ & $p_{\text {high }}[\mathrm{bar}]$ & $T_{\text {out }}\left[{ }^{\circ} \mathrm{C}\right]$ & $\eta_{\text {en }}^{\text {cycle }}[\%]$ & $\begin{array}{c}\text { Specific net power } \\
\text { output }[\mathrm{kJ} / \mathrm{kg}-\mathrm{wf}]\end{array}$ & Type & Source \\
\hline \multirow{2}{*}{$\mathrm{R} 236 \mathrm{ea}$} & 87.73 & 12.0 & 59.59 & 11.53 & 22.71 & Subcritical, & {$[8]$} \\
& 87.28 & 11.9 & 59.57 & 11.48 & 22.57 & simple & Present \\
\hline \multirow{2}{*}{$\mathrm{R} 113$} & 120 & 6.81 & $\approx 105$ & 14.45 & - & Subcritical, & {$[14]$} \\
& 120 & 6.81 & 105.83 & 14.44 & 25.37 & recuperated & Present \\
\hline \multirow{2}{*}{$\mathrm{R} 113$} & 120 & 6.81 & $\approx 110$ & 14.34 & - & Subcritical, & {$[14]$} \\
& 120 & 6.81 & 112.51 & 14.24 & 22.42 & turbine bleeding & Present \\
\hline \multirow{2}{*}{$\mathrm{CO}_{2}$} & 100 & 119 & - & 8.4 & 20.1 & Transcritical, & {$[9]$} \\
& 100 & 118.8 & 25.60 & 8.43 & 20.08 & simple & Present \\
\hline
\end{tabular}

Table 2: Validation of the single-pressure ORC-model with data published in the literature.

\subsection{Validation of the models}

The model for the subcritical, single-pressure ORC and the optimization routine are validated with the data published by Dai, Y. and Wang, J. and Gao, L. [8]. The optimization is performed for the same working conditions and for various fluids. The comparison shows very good agreement, as seen from table 2 .

Subcritical cycles without superheating are optimized by Yari [14]. Simple cycles, recuperated cycles and cycles with turbine bleeding with a fixed evaporation temperature of $120^{\circ} \mathrm{C}$ are treated. The results are given in table 2. From this table, it is concluded that the model for recuperation and turbine bleeding are validated. Cayer et al. [9] have maximised the specific net power output per unit of working fluid for a transcritical cycle with $\mathrm{CO}_{2}$ as working fluid. As seen from table 2, it can be concluded that the present model works fine for transcritical cycles.

The model of the Kalina cycle is validated by comparison to Ogriseck [5].

\subsection{Net Power Output}

In this section, two cases are investigated. In the first case, there is no constraint on the brine outlet temperature. In the second case, a minimum brine outlet temperature of $75^{\circ} \mathrm{C}$ is used. This is done to simulate cases where scaling (fouling) has to be avoided or when the brine is used for heating or cooling (absorption or adsorption cooling).

\subsubsection{Brine cooling temperature without limit}

\section{a. Single pressure}

Figure 5 shows the exergetic plant and energetic cycle efficiency for the 20 fluids with the highest power output in a single pressure level cycle for the simple configuration. The fluids are ordered from the best (R227ea) to the worst fluid (C5F12) of the 20 (in terms of exergetic plant efficiency). As mentioned in section 2 , it is the plant efficiency that should be maximized. In figure 5 it is chosen to plot the exergetic plant efficiency, because this characteristic allows an easier comparison between power plants with different brine inlet temperatures or dead-state temperatures (e.g. section 5.4). The energetic cycle efficiency is added to the figure, because this value shows that maximizing the plant efficiency is not equal to maximizing the cycle efficiency. It is also a characteristic that is often used in the literature and is added as a reference.

Although the exergetic plant efficiency decreases monotonically, the energetic cycle efficiency does not. It is seen from Eqs. (8) and (11) that the plant efficiency is the product of the cycle efficiency and the brine cooling efficiency. This means that the cycle with R115 can cool the brine further down than a cycle with R125, because both have about the same cycle efficiency, but a different plant efficiency. The other way around is also possible, as seen with R41 and R32.

In this figure, only cycles with a simple configuration are shown, because the model shows that it is not useful to use a recuperator or turbine bleeding. Recuperation and turbine bleeding can increase the cycle efficiency, but not the plant efficiency in this case. When an internal heat exchanger is used, the amount of heat transfered between the brine and the working fluid is decreased and the brine cools down less. The cycle efficiency increases, but the brine cooling efficiency decreases. The net result is zero.

The best cycles are all transcritical ones and have critical temperatures below $80^{\circ} \mathrm{C}$. The only exception is $\mathrm{R} 227 \mathrm{ea}$, which has a critical temperature of $101.75^{\circ} \mathrm{C}$. In the obtained cycle with R227ea, the expansion 


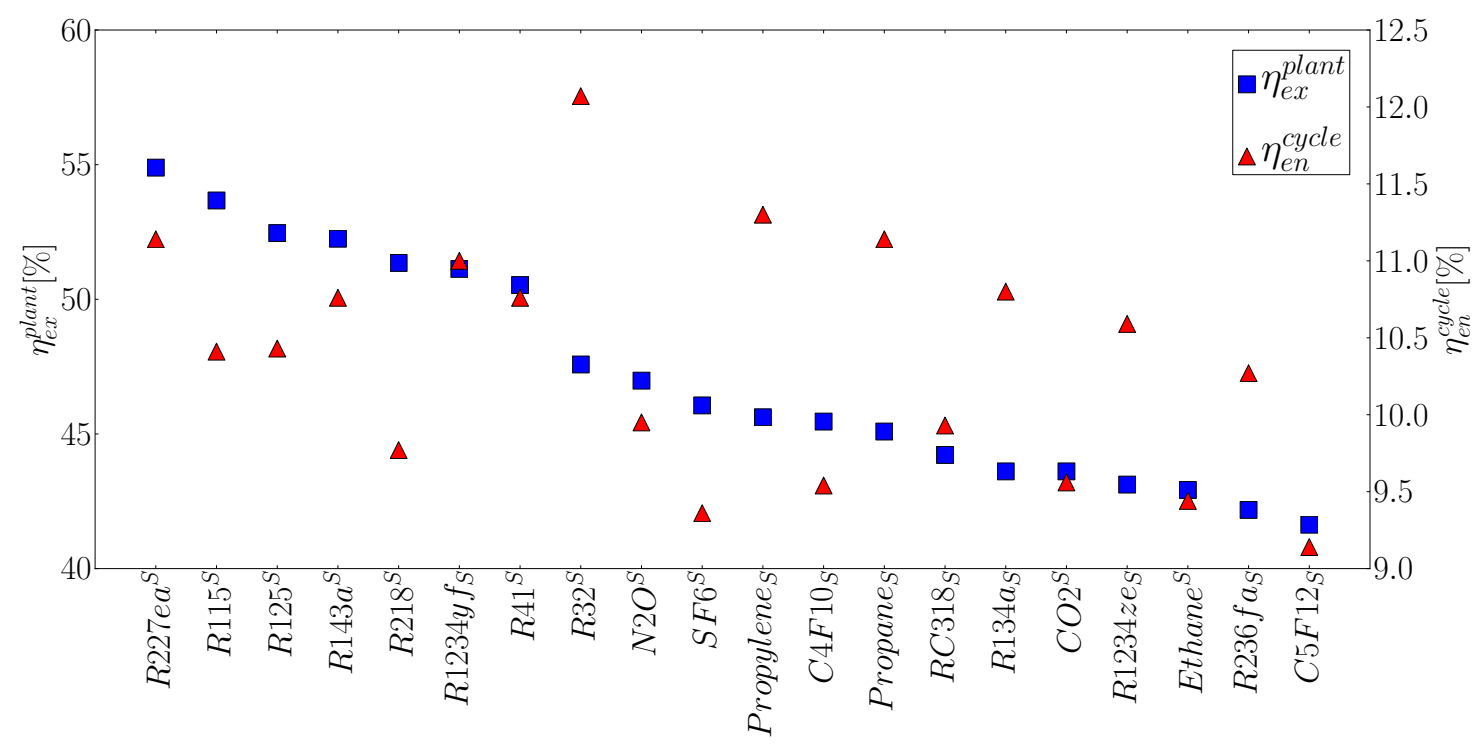

Figure 5: Exergetic plant efficiency $(\square)$ and energetic cycle efficiency $(\triangle)$ of the 20 fluids with the highest mechanical power output in a single pressure level cycle for the simple $(S)$ configuration. Subcritical cycles are denoted with a subscript $S$ and transcritical cycles with a superscript $S$.

occurs partially through the two-phase region. This has no consequences on the performance of the turbine if the outlet state of the turbine is superheated $[22,23]$. Only R236fa and C5f12 have critical temperatures equal to or higher than the brine inlet temperature.

R245fa is often used as the working fluid in ORC's. An optimization with this fluid leads to a subcritical cycle with an exergetic plant efficiency of $39.7 \%$ and an energetic cycle efficiency of $10.4 \%$. The power output of this cycle does not belong to the top-20 and is therefore not mentioned in figure 5 .

All pure fluids condense at a constant temperature, so that the cooling water temperature increases from $15^{\circ} \mathrm{C}$ to about $20^{\circ} \mathrm{C}\left(T_{\text {cond }}-\Delta T_{m i n}^{\text {cond }}\right)$. In the Kalina cycle, the minimum temperature in the condenser is assumed to be $21^{\circ} \mathrm{C}$ instead of $25^{\circ} \mathrm{C}$, so that the cooling water heats up from 15 to about $20^{\circ} \mathrm{C}$. Even with this assumption, the exergetic plant efficiency of the Kalina cycle is only $41.5 \%$. So, the Kalina cycle is even thermodynamicaly outperformed by simple subcritical ORC's. The obtained Kalina cycle, is not a "real" Kalina cycle, because the working fluid before the separator (state 5) is saturated vapor. So, a separator is not needed and a recuperated subcritical ORC with a mixture of water and ammonia with a constant concentration is obtained.

In the Kalina cycle, the temperature glide at the condenser pressure allows a high amount of recuperation. As shown in figure $4 \mathrm{~b}$, the pinch point is somewhere in the evaporator and not at the end of the economizer. This allows a higher mass flow of working fluid per unit brine and a higher power output.

Figure 6 shows the net mechanical power production and irreversibilities as a fraction of the incoming brine exergy for 4 optimized cycles. The first one is a transcritical cycle with R227ea, the second one is a subcritical cycle with propylene, the third one is the Kalina cycle and the fourth one is a subcritical cycle with R245fa, which serves as a reference. The cycle with R227ea performs the best because of the low irreversibilities created in the heat exchange between brine and working fluid and because of the high brine cooling efficiency. The pressure ratio in this cycle is high, so the irreversibilities created in the pump and turbine are high too. The combination of the high brine cooling efficiency and the average cycle efficiency causes relatively high irreversibilities in the cooling installation.

The subcritical cycle with propylene performs better than the Kalina cycle because of the higher brine cooling efficiency and the lower irreversibilities created in the high-pressure heat exchange $\left(\dot{I}_{H X}\right.$ and $\left.\dot{I}_{\text {recup }}\right)$. In the Kalina cycle, the lower irreversibilities generated in the condenser (temperature glide), turbine and pump cannot compensate this. The cycle with R245fa produces less power than the other cycles because 


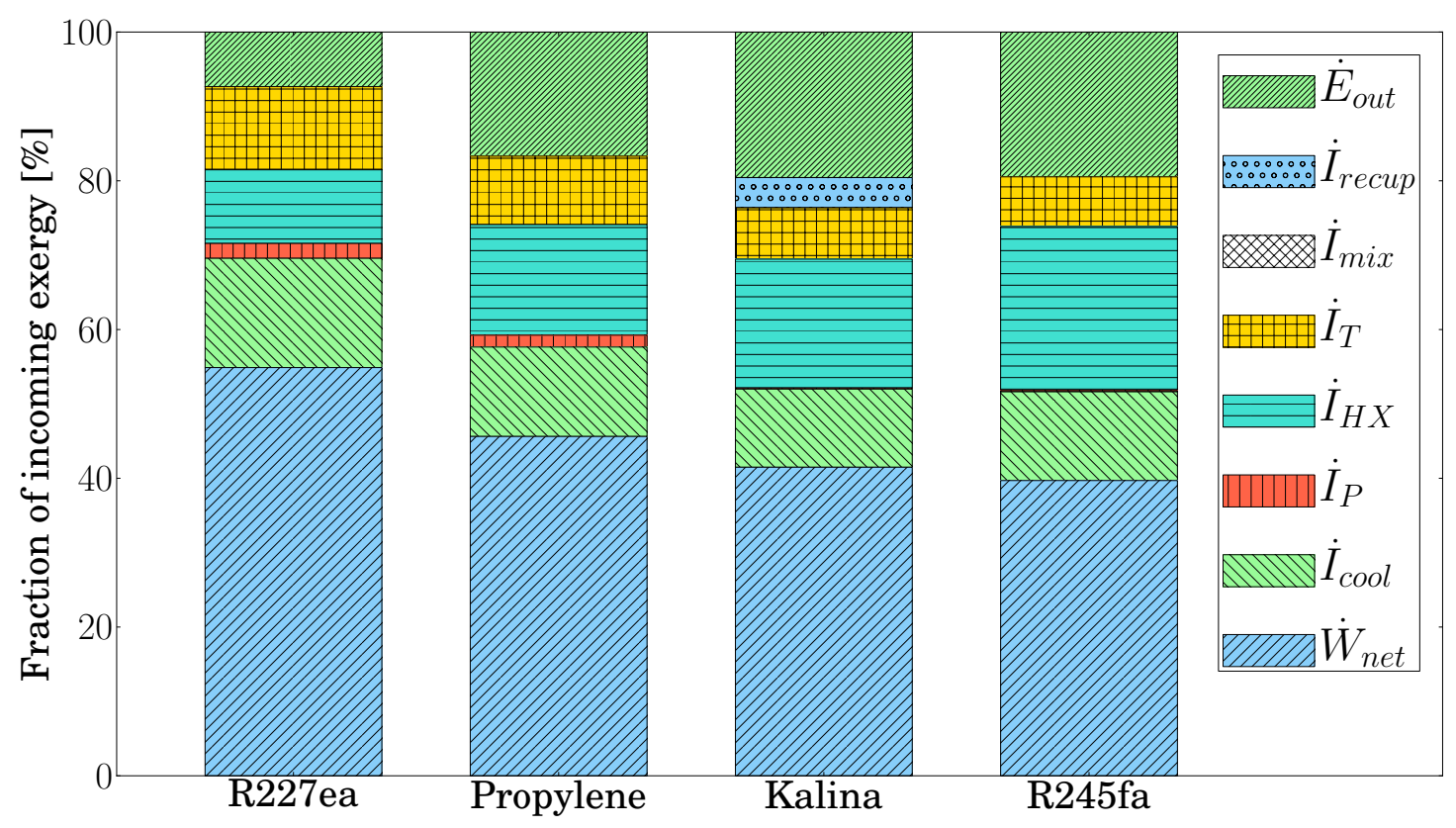

Figure 6: Net mechanical power production and irreversibilities created, as fraction of the incoming brine exergy for the optimum transcritical cycle with R227ea, the optimum subcritical cycle with propylene, the optimum Kalina cycle and the optimum cycle with R245fa as a reference.

of the very high irreversibilities created in the heat exchanger. This is a consequence of the high heat of vaporization of R245fa. To cool the brine sufficiently down, the optimum evaporation temperature should be low and a high ammount of irreversibilities is created in the heat exchanger.

One of the advantages of the Kalina cycle would be the temperature glide. This temperature glide causes a low creation of irreversibilities in the condenser, but not in the high-pressure heat exchanger. Some simple subcritical ORC's even outperform the Kalina cycle considered in this context. This comparison is only thermodynamical, so no economic conclusions are made.

\section{b. Dual pressure}

It is also possible to use more than 1 pressure level. The exergetic plant and energetic cycle efficiency for the 20 fluids with the highest power output in a dual-pressure level cycle are shown in figure 7. Again, only the simple configuration is shown because of the same reason as before.

The cycles with the highest mechanical power output are almost all a combination of a subcritical cycle with a transcritical one, but the addition of the subcritical part does not improve the plant efficiency very much (e.g. for R227ea an increase of $3 \%$ is obtained by using 2 pressure levels instead of one). For subcritical cycles, the effect is much stronger. The dual-pressure level cycle with R134a produces almost $20 \%$ more mechanical power than the single-pressure level. Because of the strong improvement of the subcritical cycles and the poor improvement of the transcritical cycles, the difference between the best and the worst fluid/cycle becomes smaller. The best 15 fluids have an exergetic efficiency above $50 \%$. So, it can be concluded that subcritical cycles with two pressure levels are almost as efficient as transcritical cycles.

For the single-pressure cycle in figure 5 , many fluids with a low critical temperature like $\mathrm{R} 41, \mathrm{~N}_{2} \mathrm{O}, \mathrm{SF} 6, \mathrm{CO}_{2}$ an Ethane perform well. Their optimum cycle is a transcritical one, with a pressure much above their critical pressure. Due to this high pressure, the irreversibilities created in the pump and the turbine are high. When two pressure levels are allowed (figure 7), most of these fluids are not among the 20 best performing fluids and are replaced by fluids with a higher critical temperature like R22, C4F10,R124,R12,R236ea and Isobutane. Their critical temperature ranges from 110 to $140^{\circ} \mathrm{C}$ and the both pressure levels are subcritical. 


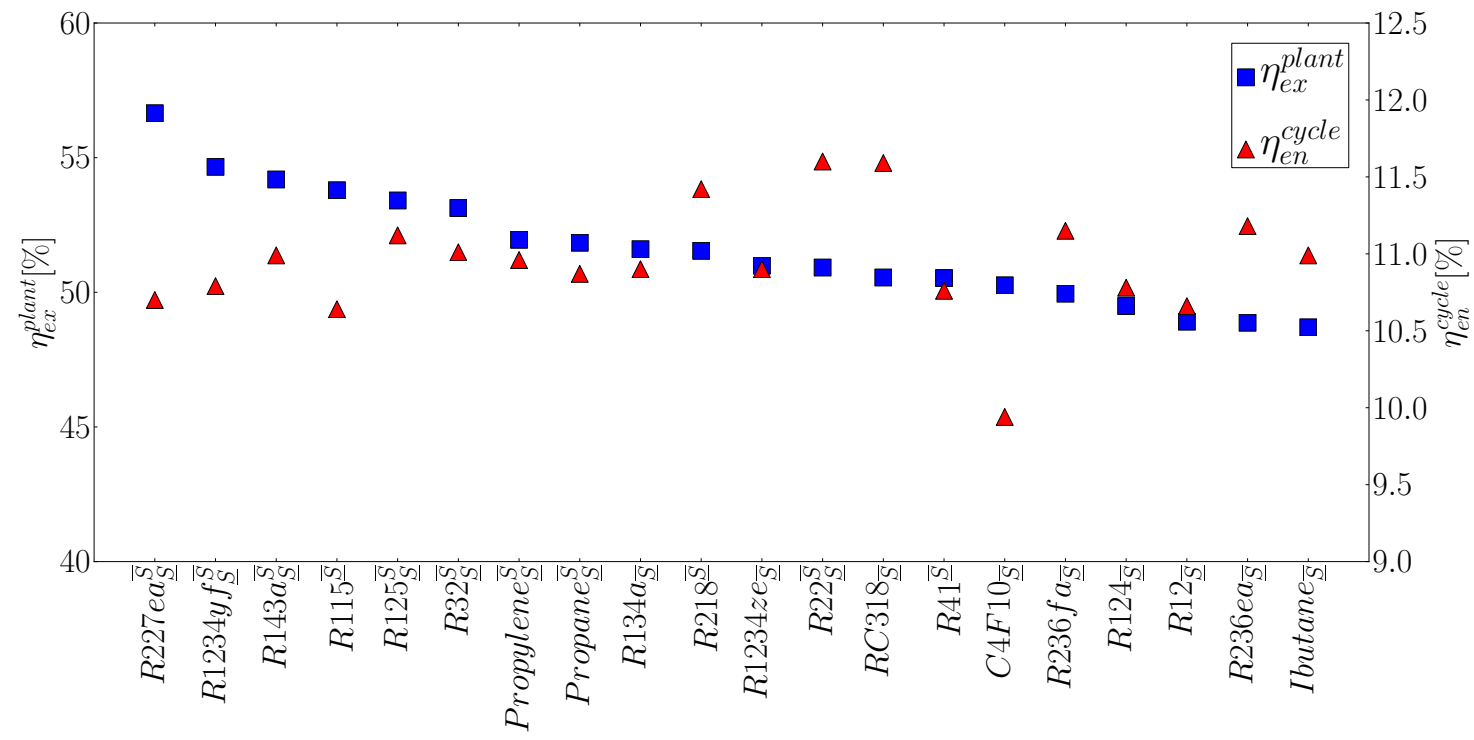

Figure 7: Exergetic plant efficiency $(\square)$ and energetic cycle efficiency $(\triangle)$ of the 20 fluids with the highest mechanical power output in a dual-pressure level cycle for the simple configuration. Subcritical cycles are denoted with a subscript $S$ and transcritical cycles with a superscript $S$. The low-pressure sub-cycle is underlined, the high-pressure sub-cycle has an overbar.

For the single-pressure level cycles (figure 5), the energetic cycle efficiency fluctuates strongly. For the dual-pressure level cycles, the energetic cycle efficiency is more constant and is about $11 \%$. So, the extra pressure level does not only reduce the difference in plant efficiency, but also in cycle efficiency.

\section{c. Triple and multi-pressure}

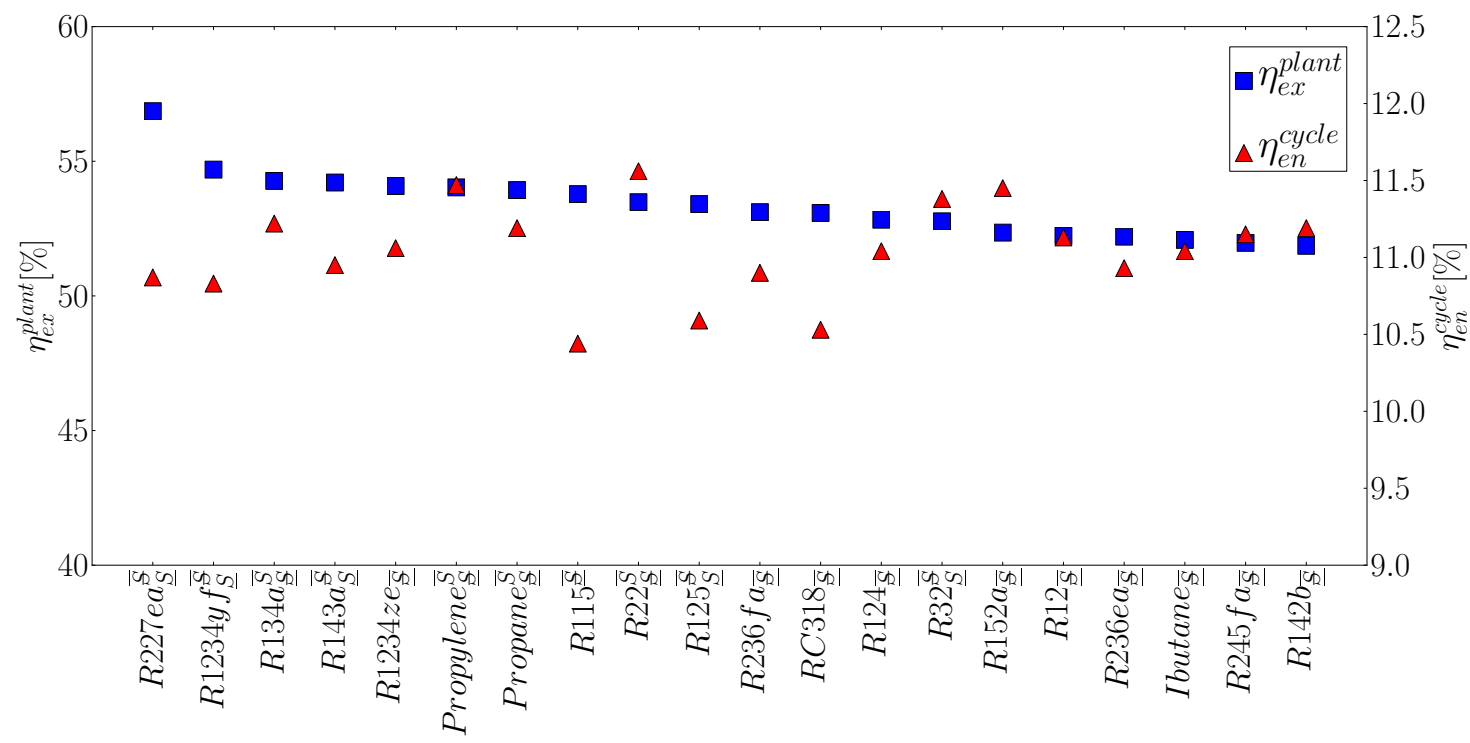

Figure 8: Exergetic plant efficiency $(\square)$ and energetic cycle efficiency $(\triangle)$ of the 20 fluids with the highest mechanical power output in a triple-pressure level cycle for the simple configuration. Subcritical cycles are denoted with a subscript $S$ and transcritical cycles with a superscript $S$. The low-pressure sub-cycle is underlined, the intermediate pressure sub-cycle is lined through and the high-pressure sub-cycle is overlined. 
Figure 8 shows the efficiencies when a third pressure level is added. The exergetic plant efficiency improves a bit for the subcritical cycles, but the effect is much less than the addition of the second pressure level. The difference in performance between the fluids has become smaller and the energetic cycle efficiency is about $11 \%$. Addition of more pressure levels will improve the power plant performance, but every extra pressure level will have less effect. By addition of this extra pressure level, fluids with higher critical temperatures (e.g. R152a, R245fa, etc.) are performing relatively better, replacing fluids with lower critical pressures (e.g. R41, R218, etc.). Figure 9 shows the exergetic efficiency of a multi-pressure cycle with isobutane for different pressure levels. The improvement of the addition of an extra pressure level is shown on the right hand side. This improvement is defined as:

$$
\epsilon_{i}=\frac{\dot{W}_{n e t}^{i}-\dot{W}_{n e t}^{i-1}}{\dot{W}_{n e t}^{i-1}}
$$

with $\epsilon_{i}$ the improvement of addition of the $\mathrm{i}^{\text {th }}$ pressure level and $\dot{W}_{n e t}^{i}$ the net power output of a cycle with $i$ pressure levels. From the figure, it is seen that the addition of an extra pressure level is thermodynamically useful, but the effect decreases with increasing number of pressure levels.

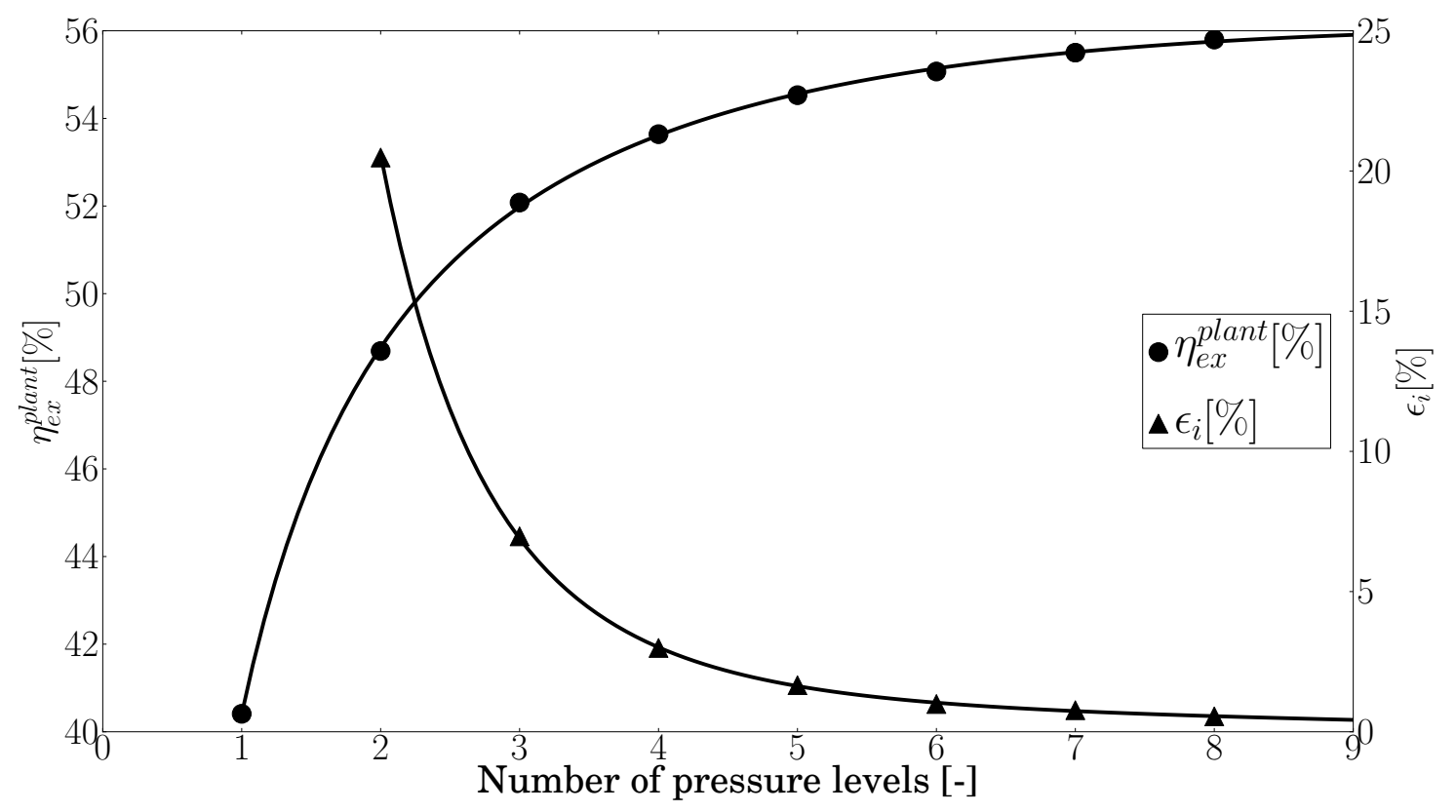

Figure 9: Exergetic plant efficiency (o) of a multi-pressure simple cycle with isobutane in function of the number of pressure levels. The improvement of an extra pressure level is shown $(\triangle)$.

Figure 10 shows the net mechanical power production and irreversibilities created in the single, dual and triple-pressure cycle with isobutane. The addition of extra pressure levels improves the brine cooling efficiency and decreases the irreversibility created in the high-pressure heat exchanger. Because of the higher pumping power and turbine power, also more irreversibilities are created in these components.

\subsubsection{Constraint on brine outlet temperature}

Figure 11 shows the exergetic plant and energetic cycle efficiencies in the case when the minimum brine outlet temperature is limited to $75^{\circ} \mathrm{C}$. Again the 20 fluids with the highest mechanical power output in a single pressure level cycle are given. In this case, the cycles with recuperation or turbine bleeding can have higher power outputs than the simple one. This follows from equation (11). The brine cooling is limited to a temperature which is higher than the brine cooling temperature in the case without constraint. So, in every cycle the brine will be cooled to $75^{\circ} \mathrm{C}$ and the brine cooling efficiency is fixed. Recuperation and turbine 


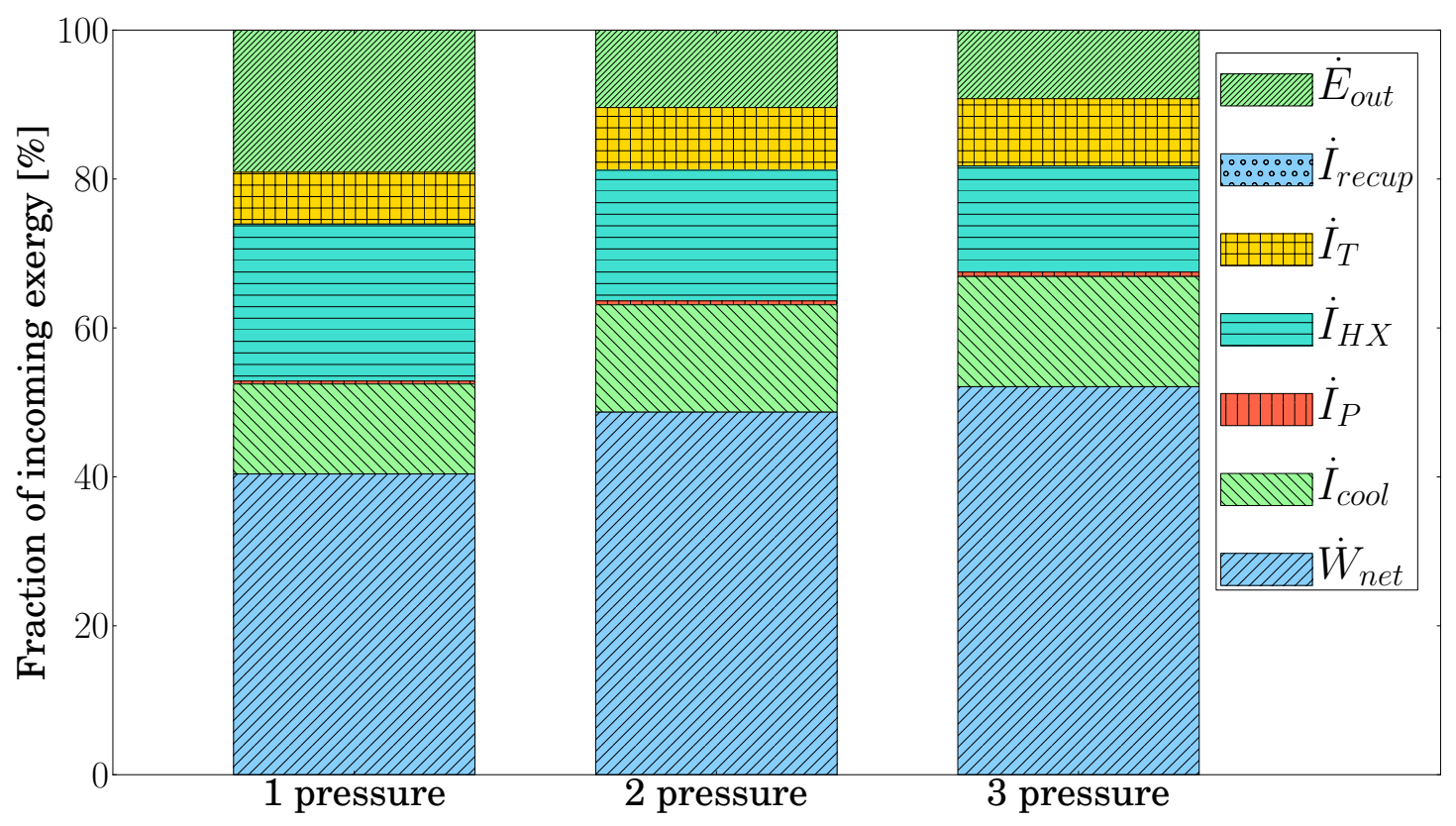

Figure 10: Net mechanical power production and irreversibilities created, as fraction of the incoming brine exergy for the optimum single, dual and triple-pressure cycle with isobutane.

bleeding can improve the cycle efficiency; so in the limited case, they can improve the plant efficiency. This also explains the strong correlation between the cycle and plant efficiency in figure 11. The often used R245fa, which can be seen as a reference case, performs best in a subcritical, recuperated cycle, with an exergetic plant efficiency of $37.4 \%$ and an energetic cycle efficiency of $12.6 \%$ (not in the figure).

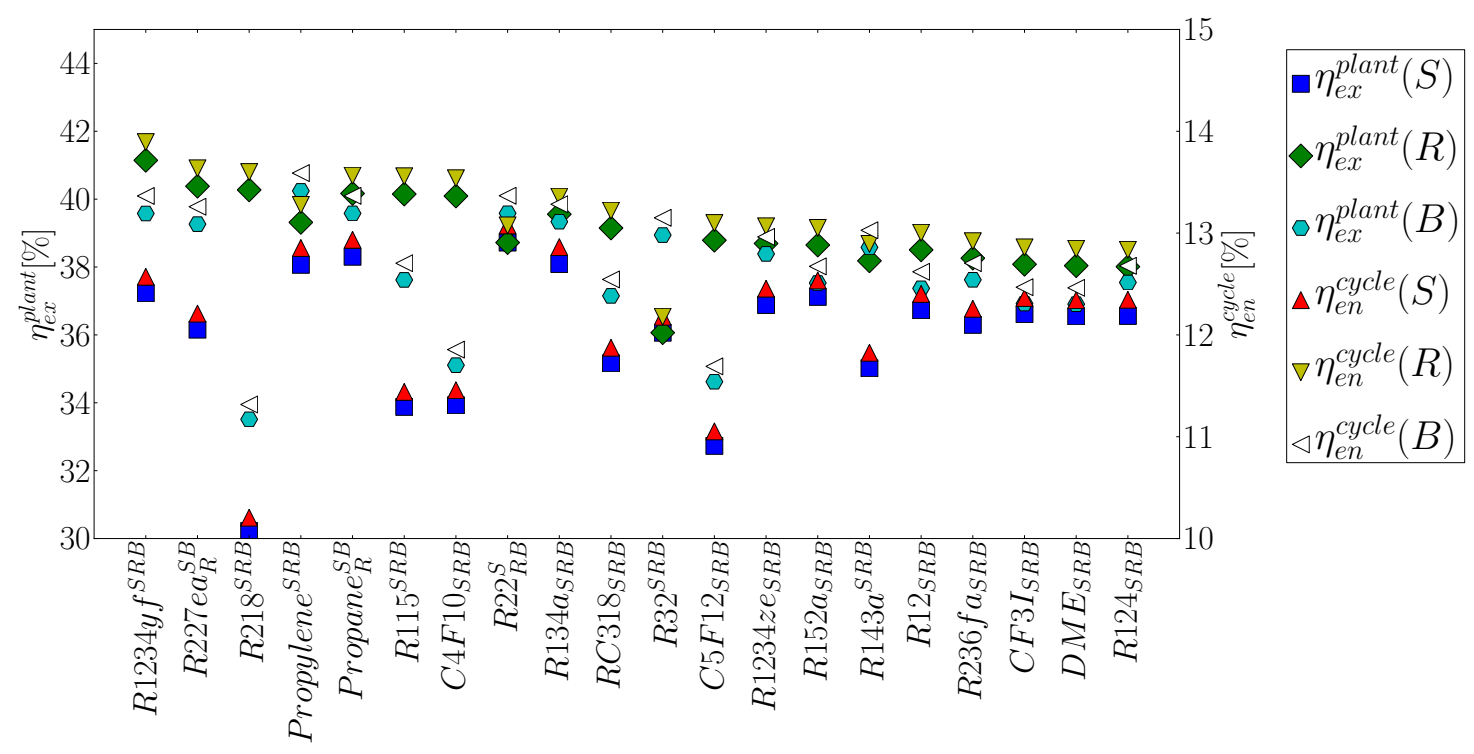

Figure 11: Exergetic plant efficiency and energetic cycle efficiency of the 20 fluids with the highest mechanical power output in a single pressure level cycle with a limited brine outlet temperature of $75^{\circ} \mathrm{C}$. $S$ stands for the simple cycle, $R$ for the cycle with recuperation and $B$ for the cycle with turbine bleeding. Subcritical cycles are denoted with a $s u b s c r i p t$, transcritical ones with a superscript. 
As seen in figure 11, recuperation is always useful, except for R22 and R32. These are very wet fluids, so they would need very high superheating to be able to recuperate. The gain in power output because of the recuperation is apparently lower than the loss in power output due to the extra superheating.

The transcritical cycles are not as superior as in the unconstrained case. For recuperation or turbine bleeding, superheating before the turbine is often needed. The maximum temperature of the working fluid is limited by the temperature of the brine. So, when superheating is used, the maximum pressure has to decrease. Therefore, only for fluids with a low critical pressure, transcritical cycles with recuperation or turbine bleeding are the optimum. Fluids with very low critical temperatures like $\mathrm{R} 41, \mathrm{~N}_{2} \mathrm{O}$ and $\mathrm{CO}_{2}$, which perform well in the unconstrained case with one pressure level, are not the best choice in the constrained case. Their critical temperature is very low $\left(30-45^{\circ} \mathrm{C}\right)$ and the maximum pressure in the cycle is much above the critical pressure to decrease the amount of irreversibilities created in the heat exchanger. Due to this high pressure, the temperature rise in the pump is high and recuperation becomes hard. Turbine bleeding is also not succesful enough. The bleeding pressure is limited from above by the critical pressure. For the fluids mentioned above, the critical pressure is low and the temperature of state 3 will be low too. This leads to higher irreversibilities in the heat exchange and a low plant efficiency. It can be concluded that the optimum fluids in the constrained case have higher critical temperatures than in the unconstrained one.

For the optimization of the Kalina cycle with a constrained brine outlet temperature, a minimum temperature in the condenser of $21^{\circ} \mathrm{C}$ is used. Because of the high cycle efficiency of the Kalina cycle, it performs relatively better than in the unconstrained case. An exergetic efficiency of almost $40 \%$ is obtained, which is almost the same as for the unconstrained case. The performance of the Kalina cycle is in this case similar to the best ORC's, mainly because of the temperature glide in the condenser which allows a lower minimum temperature in the condenser. When the minimum condenser temperature is limited to $25^{\circ} \mathrm{C}$, an exergetic efficiency of $37 \%$ is obtained.

The effect of an extra pressure level is shown in figure 12. It shows that the 20 best fluids are optimum when using recuperation and the difference in performance between the fluids is very small. Turbine bleeding is almost always better than the simple cycle, except for the very dry fluid perfluorobutane (C4F10). By adding a pressure level, fluids with high critical temperature become relatively better.

The transcritical cycles have not much benefit from the extra pressure level. Because of the small difference in performance between transcritical and subcritical cycles for one pressure level, the optimum cycles for 2 pressure levels are almost all subcritical. The addition of more pressure levels has the same effect as in the unconstrained case.

\subsection{Influence of changing parameters}

In this section, the influence of some parameters is investigated. These parameters are the brine inlet temperature, the constraint on the brine outlet temperature, the condenser temperature and the minimum temperature difference between the brine and the working fluid. These parameters are varied, while all other parameters have the value given in table 1 . For every influencing parameter, the effect on one or a few of the best ORC's is shown. Comparison with the Kalina cycle is added.

\subsubsection{Brine inlet temperature}

The brine inlet temperature is varied from 100 to $150^{\circ} \mathrm{C}$. There is no constraint on the brine outlet temperature and for every brine inlet temperature, the optimum working fluid is selected. The exergetic efficiency with these fluids is given in figure 13. It is seen that the optimum fluid depends strongly on the brine inlet temperature and fluids with a higher critical temperature perform relatively better when the brine inlet temperature is increased. For the fluids R227ea and RC318, the exergetic plant efficiency increases almost linear for low brine inlet temperatures (subcritical cycles). The transition of a subcritical to a transcritical cycle is discontinuous, followed by a weak rise in the efficiency for higher temperatures. For even higher temperatures the exergetic plant efficiency is almost constant and starts to decrease. The specific power output on the contrary keeps increasing (not in figure). The plant efficiency decreases, but the increase of the incoming exergy of the brine is higher (see equation (6). The investigated Kalina cycle is added as a comparison and is clearly outperformed by the ORC's. The figure also shows that the maximum exergetic 


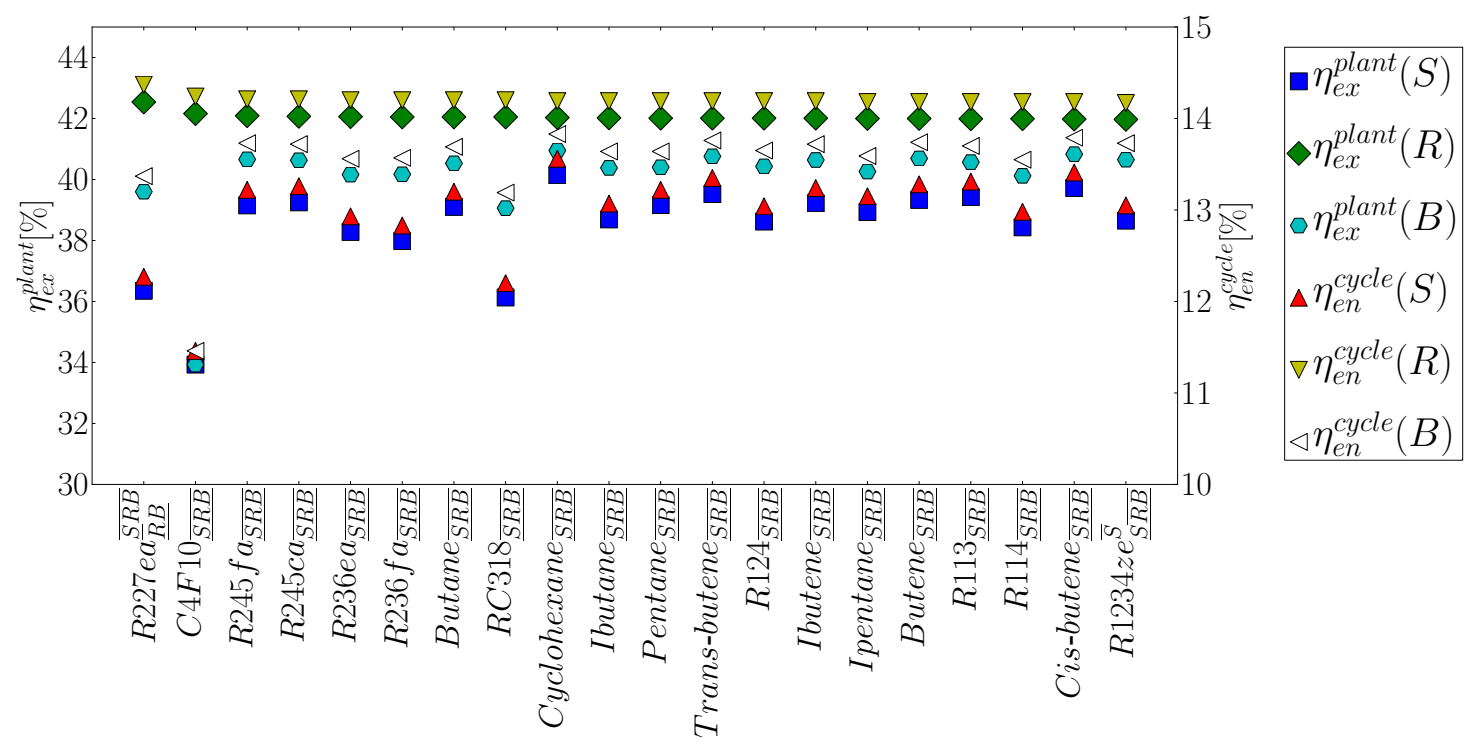

Figure 12: Exergetic plant efficiency and energetic cycle efficiency of the 20 fluids with the highest power output in a dual pressure level cycle with a limited brine outlet temperature of $75^{\circ} \mathrm{C} . S$ stands for the simple cycle, $R$ for the cycle with recuperation and $B$ for the cycle with turbine bleeding. Subcritical cycles are denoted with a subscript, transcritical ones with a superscript. The low pressure sub-cycle is underlined, the high pressure sub-cycle is overlined.

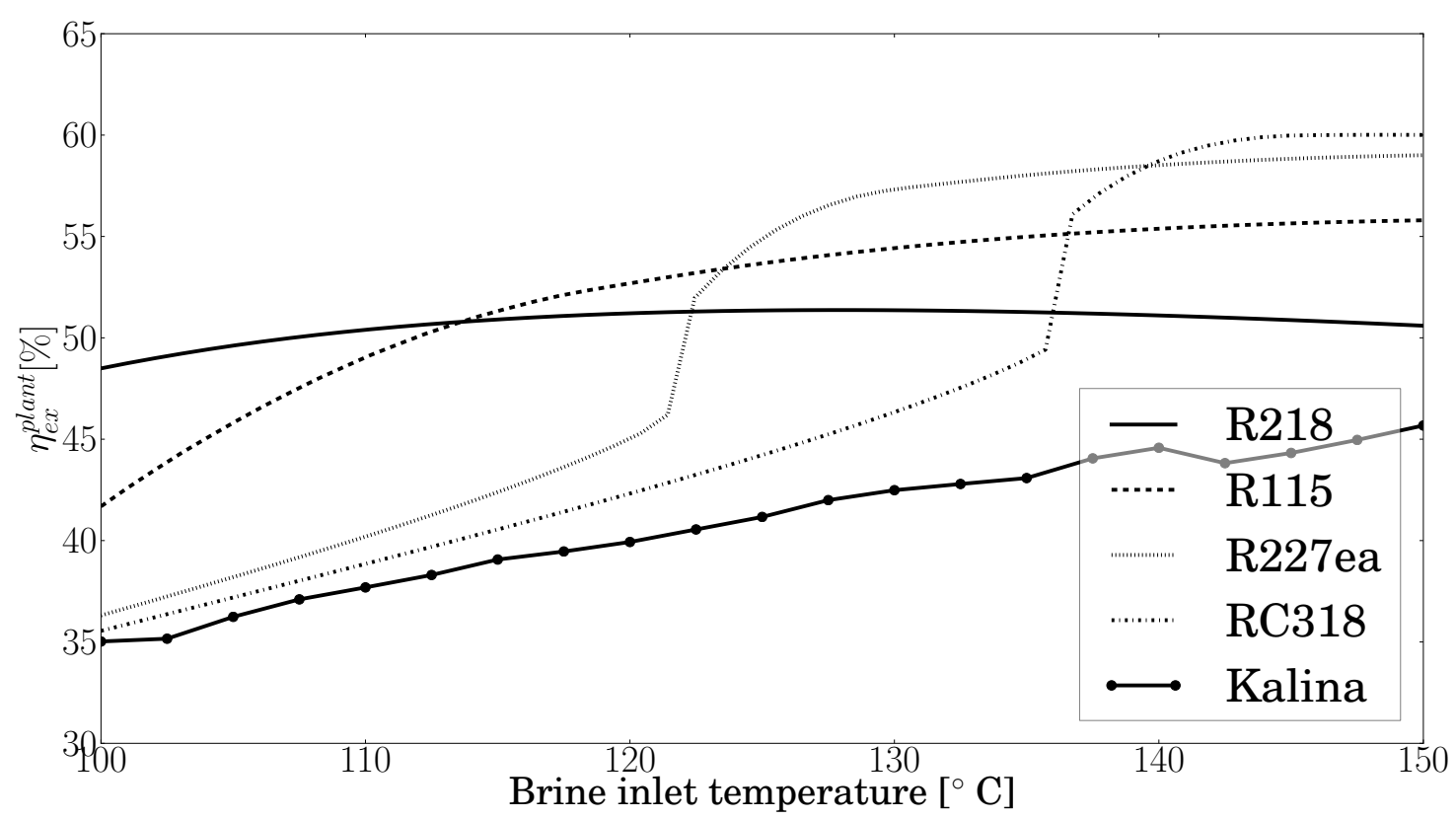

Figure 13: Exergetic efficiency of the temperature-dependent optimum fluids without constraint on the brine outlet temperature. The Kalina cycle is added as a comparison.

efficiency depends on the brine inlet temperature. This is because of the fixed temperature differences in the heat exchangers, which are relatively more important for the low brine inlet temperatures.

In a second case, the minimum brine outlet temperature is limited to $75^{\circ} \mathrm{C}$. These results are given in figure 14. The exergetic efficiency rises with brine inlet temperature, because the available brine temperature drop $T_{\text {in }}-T_{\text {out }}$ rises linearly for a fixed $T_{\text {out }}$. For the constrained case, there is no clear transition from a 


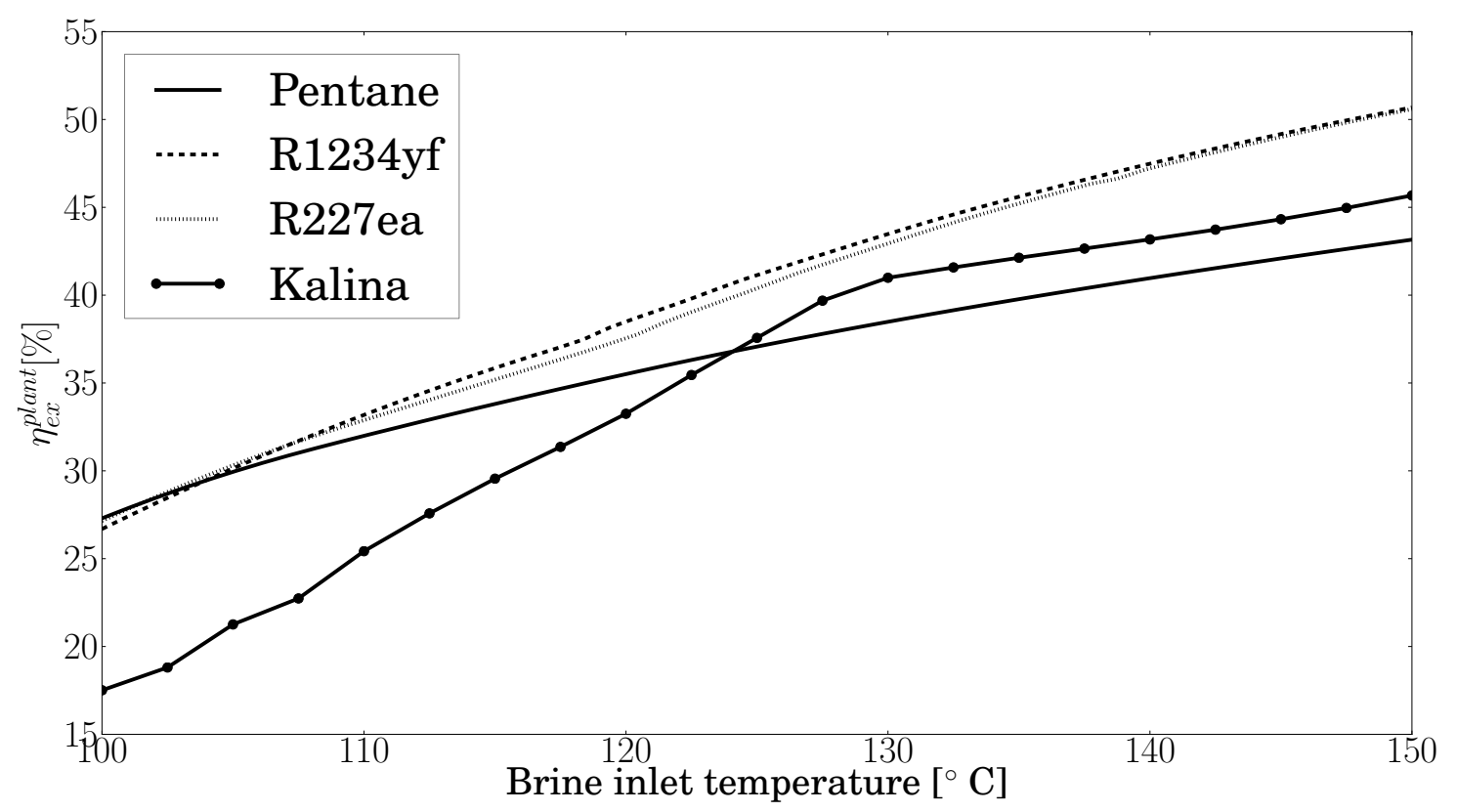

Figure 14: Exergetic efficiency of the brine inlet temperature-dependent optimum fluids (all recuperative), for a brine outlet temperature limit of $75^{\circ} \mathrm{C}$. The Kalina cycle is added as a comparison.

subcritical to a transcritical cycle. Again the investigated Kalina cycle is added as a comparison. For higher brine inlet temperatures, the Kalina cycle performs almost as good as the best ORC's.

\subsubsection{Constraint on brine outlet temperature}

The constraint on the brine outlet temperature is varied between 25 and $100^{\circ} \mathrm{C}$. Both the temperature at which scaling occurs and the temperature of a possible heat demand depend strongly on the location (brine composition, old or new houses, etc.). Therefore, a wide range in brine outlet temperatures is chosen and the influence is investigated. Figure 15 shows the exergetic efficiency for 4 single-pressure, recuperated ORC's and the Kalina cycle considered. In the unconstrained case, the brine outlet temperature is about $50-70^{\circ} \mathrm{C}$, depending on the fluid. So, the exergetic plant efficiency is only influenced by the constraint when the constraint temperature is above the unconstrained brine outlet temperature.

The fluids shown are the best ones for a certain range in brine outlet temperature limit and a comparison with the Kalina cycle is made. For relatively low brine outlet temperature limits, the best fluids for the unconstrained case (low critical temperature) perform the best. But when the constrained brine outlet temperatures become high, fluids which perform badly in the unconstrained case (high critical temperature) become the better ones. Up to an outlet temperature of $60^{\circ} \mathrm{C}$, the efficiency is decreased by only $10 \%$, but for higher temperatures the efficiency decreases strongly, because the available temperature drop becomes small. For constrained brine outlet temperatures around $70^{\circ} \mathrm{C}$, the Kalina cycle performs equally well as the best ORC's, but for lower or higher temperatures the ORC's are the better choice.

\subsubsection{Condenser temperature}

For the ORC's the condenser temperature is varied from 20 to $35^{\circ} \mathrm{C}$. Figure 16 shows the exergetic plant and energetic cycle efficiency for a simple cycle with R227ea in comparison to the standard case $\left(T_{\text {cond }}=\right.$ $25^{\circ} \mathrm{C}$ ). Also the outlet temperature of the brine is shown. The energetic cycle efficiency decreases with increasing condenser temperature, because the cycle low temperature heat reservoir increases in temperature $\left(T_{\text {cond }}\right)$. The brine outlet temperature increases almost linearly with the condenser temperature; for R227ea the temperature difference between the condenser temperature and the brine outlet temperature is about $15^{\circ} \mathrm{C}$. 


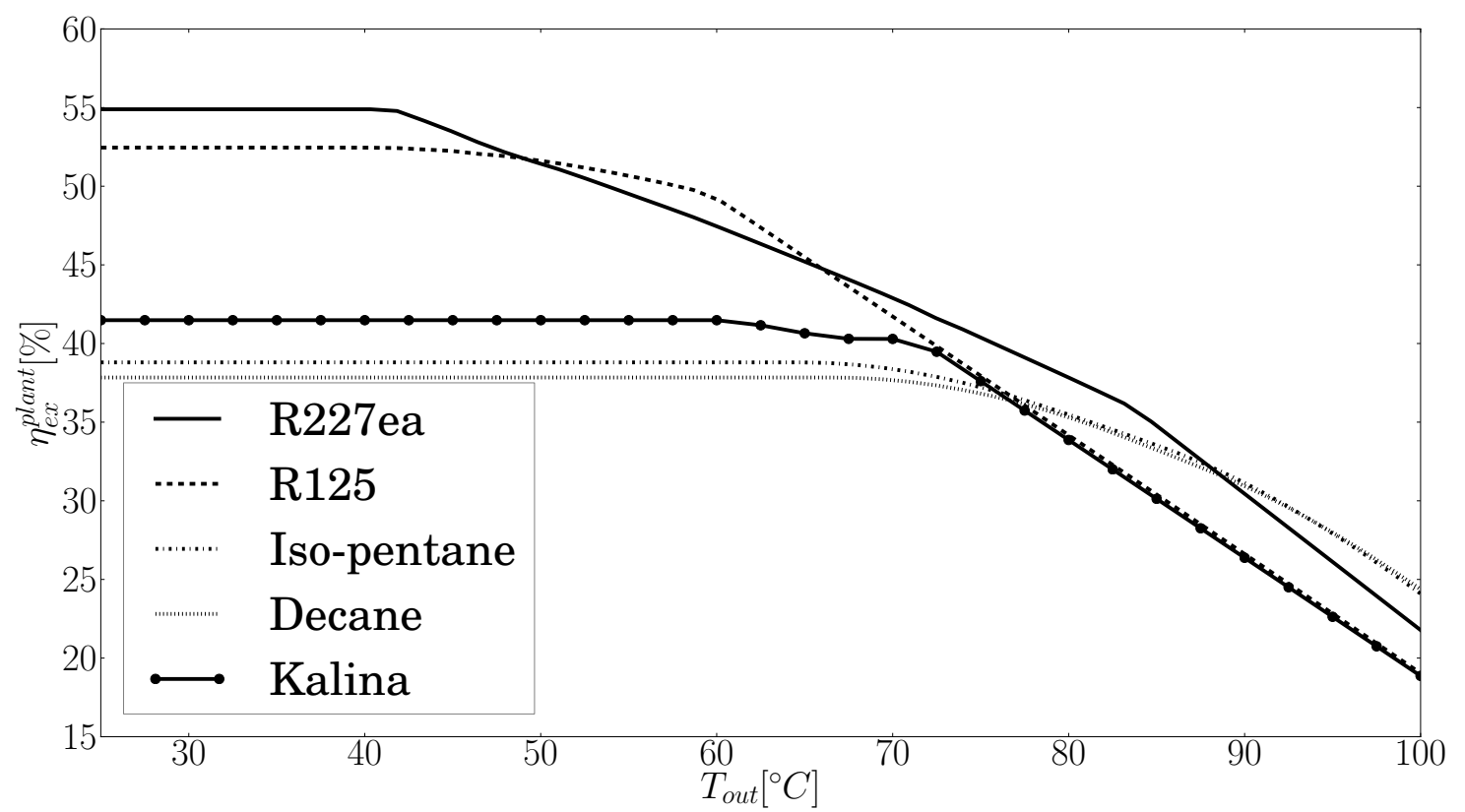

Figure 15: Exergetic efficiency of R227ea, R125, isopentane, decane and Kalina in function of the limit on the brine outlet temperature. The brine inlet temperature is fixed at $125^{\circ} \mathrm{C}$.

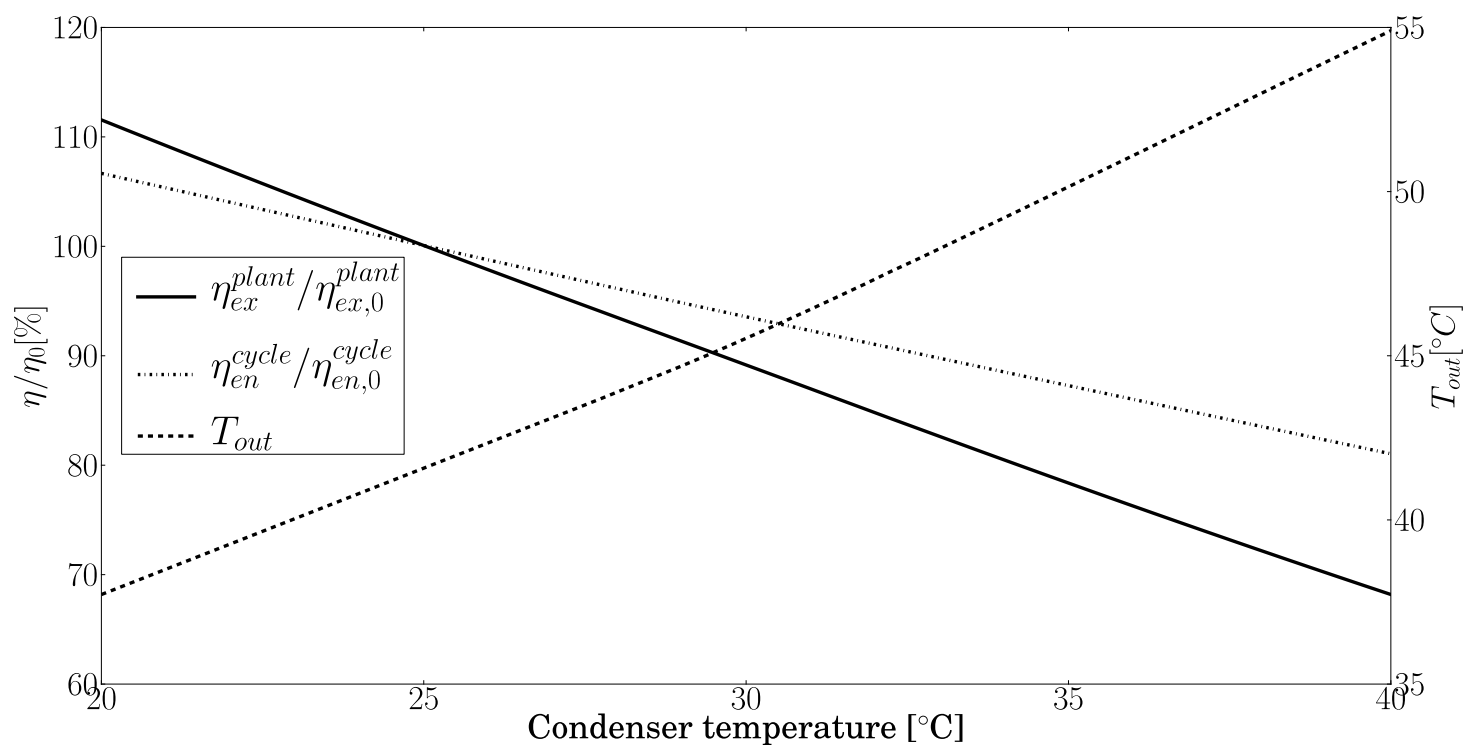

Figure 16: Exergetic plant efficiency $\eta_{e x}^{\text {plant }}$, energetic cycle efficiency $\eta_{e n}^{\text {cycle }}$ and brine outlet temperature in function of the condenser temperature for a cycle with R227ea. $\eta_{e x, 0}^{\text {plant }}$ and $\eta_{e n, 0}^{\text {cycle }}$ are the exergetic plant and energetic cycle efficiency when the condenser temperature is $25^{\circ} \mathrm{C}$, respectively.

The exergetic plant efficiency decreases strongly with increasing condenser temperature, because the cycle efficiency decreases and the brine outlet temperature increases. This strong, linear decrease has earlier been described [24]. The figure shows that increasing the condenser temperature with $10^{\circ} \mathrm{C}$ decreases the plant efficiency with about $20 \%$. 


\subsubsection{Minimum temperature difference in $H X$}

The minimum temperature difference in the heat exchanger between brine and working fluid $H X$ is varied from 1 to $20^{\circ} \mathrm{C}$ for the unconstrained case. The exergetic plant efficiency, energetic cycle efficiency and brine outlet temperature for cycles with R227ea are shown in figure 17. In the reference state for the efficiencies, the temperature difference is $5^{\circ} \mathrm{C}$.

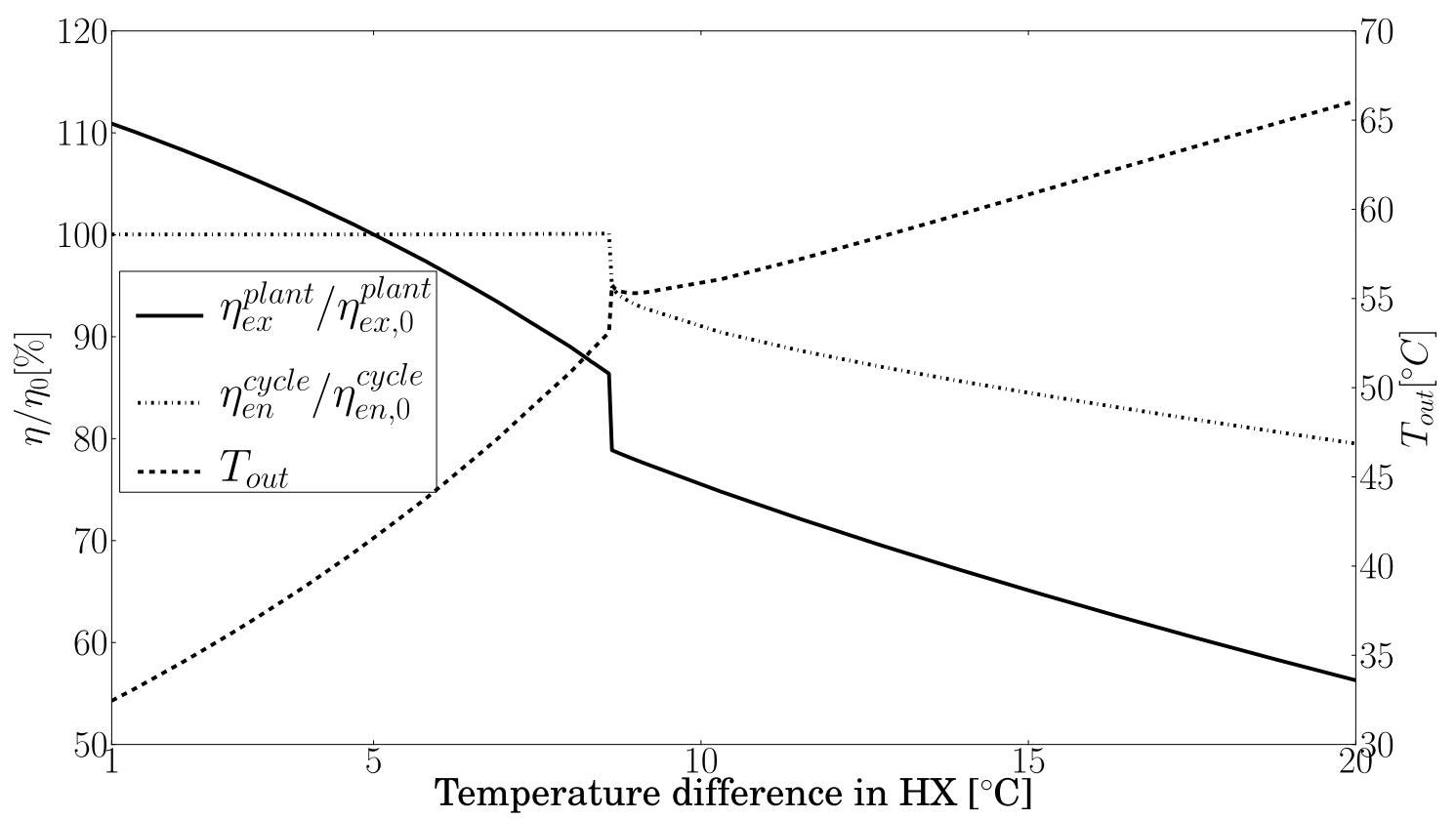

Figure 17: Exergetic plant efficiency, energetic cycle efficiency and brine outlet temperature for cycles with R227ea as a function of the temperature difference in the heat exchanger $H X$.

For low temperature differences, the cycle is of the transcritical type. The cycle efficiency is constant, because the cycle itself (pressure, maximum temperature) does not change. So, the variation in plant efficiency is completely determined by the variation in brine outlet temperature for this transcritical cycle.

At a temperature difference of about $8.5^{\circ} \mathrm{C}$ there is a sudden drop in the cycle efficiency and an increase in the outlet temperature due to the transition from a transcritical to a subcritical cycle for this fluid. For the subcritical cycle the cycle efficiency does depend on the temperature difference, because the pinch point is at the beginning of the evaporator. When the temperature difference increases, the maximum pressure of the cycle has to decrease to allow a reasonable brine cooling efficiency.

\section{Conclusions}

For a geothermal power plant, it is important to maximize the plant efficiency, which is the product of the cycle efficiency and the brine cooling efficiency. So, the brine should be cooled down as much as possible and the heat added to the cycle should be converted to mechanical power as efficient as possible. The exergetic plant efficiency $\eta_{e x}^{\text {plant }}$ describes how good a certain cycle approaches the ideal one.

Transcritical and multi-pressure subcritical ORC's are in most cases the best performing cycles and can achieve exergetic plant efficiencies of more than 50\%. They outperform the investigated Kalina cycle for low minimum brine outlet temperatures. For brine outlet temperatures around $70^{\circ} \mathrm{C}$, the best ORC's and the Kalina perform similarly.

When there is no constraint on the brine outlet temperature, recuperation or turbine bleeding are not useful. Both techniques improve the cycle efficiency, but the brine cooling efficiency decreases and the combination of these two effects has zero influence on the plant efficiency. A constraint on the brine outlet 
temperature causes a strong decrease in the power plant output, but in this case the decrease can partly be compensated by the use of recuperation or turbine bleeding. The Kalina cycle performs relatively better when the brine outlet temperature is limited.

The choice of the optimum working fluid depends strongly on the conditions. In the single-pressure, unconstrained case, fluids with a low critical temperature perform the best and a transcritical cycle is optimum. When an extra pressure level is allowed or a constraint is added to the brine outlet temperature, fluids with higher critical temperatures become relatively better and (multipressure) subcritical cycles are equally good or better than transcritical cycles.

The maximum theoretical temperature drop of the brine is low, because of the low brine inlet temperature. A small increase in the condenser temperature or the pinch point temperature difference, have a relatively strong influence on the available temperature drop of the brine and therefore also on the plant efficiency. So, for low temperature heat sources, it is very important to have a low condenser temperature and pinch point temperature difference. 


\section{Nomenclature}

$\begin{array}{ll}e & \text { Specific exergy }[\mathrm{kJ} / \mathrm{kg}] \\ \dot{E}_{\text {available }} & \text { Available exergy }[\mathrm{kW}] \\ h & \text { Specific enthalpy }[\mathrm{kJ} / \mathrm{kg}] \\ \dot{I} & \text { Irreversibility }[\mathrm{kW}] \\ \dot{m} & \text { Mass flow }[\mathrm{kg} / \mathrm{s}] \\ \text { ORC } & \text { Organic Rankine cycle } \\ p & \text { Pressure }[\mathrm{bar}] \\ \dot{Q} & \text { Heat flow }[\mathrm{kW}] \\ s & \text { Specific entropy }[\mathrm{kJ} / \mathrm{kgK}] \\ T & \text { Temperature }\left[{ }^{\circ} \mathrm{C}\right] \\ \dot{W} & \text { Mechanical power }[\mathrm{kW}] \\ x & \text { Vapor fraction }[-]\end{array}$




\section{Sub-and superscripts}

$\begin{array}{ll}0 & \text { Dead state } \\ 1-11 & \text { Reference } \\ \text { brine } & \text { Number of the state } \\ \text { cond } & \text { Condenser } \\ \text { cooling } & \text { Cooling (installation) } \\ \text { cycle } & \text { Cycle } \\ \text { en } & \text { Energetic } \\ \text { ex } & \text { Exergetic } \\ \text { high } & \text { Higher } \\ \text { HX } & \text { Heat exchanger between brine and working fluid } \\ i & \text { Number of pressure level } \\ \text { in } & \text { Inlet } \\ \text { int } & \text { Intermediate } \\ \text { low } & \text { Lower } \\ \text { min } & \text { Minimum } \\ \text { mix } & \text { Mixing } \\ \text { net } & \text { Netto } \\ \text { out } & \text { Outlet } \\ \text { P } & \text { Pump } \\ & \\ \text { plant } & \text { Plant } \\ \text { recup } & \text { Recuperator } \\ \text { s } & \text { Isentropic } \\ \text { T } & \text { Turbine } \\ \text { wf } & \text { Working fluid } \\ \end{array}$




\title{
Greek symbols
}

\author{
$\Delta$ Difference \\ $\eta \quad$ (Isentropic) efficiency [-] \\ $\epsilon_{i} \quad$ Improvement of addition of the $\mathrm{i}^{\text {th }}$ pressure level \\ $\varepsilon \quad$ Fraction of mass flow through turbine (Kalina) [-] \\ Fraction of mass flow extracted from turbine (turbine bleeding) [-]
}

\section{Acknowledgments}

Daniël Walraven is supported by a VITO doctoral grant.

\section{References}

[1] J. Tester, B. Anderson, A. Batchelor, D. Blackwell, R. DiPippo, E. Drake, J. Garnish, B. Livesay, M. Moore, K. Nichols, The Future of Geothermal Energy: Impact of Enhanced Geothermal Systems (EGS) on the United States in the 21st Century, Tech. Rep., Massachusetts Institute of Technology, Massachusetts, USA, 2006.

[2] H. Paschen, D. Oertel, R. Grünwald, Möglichkeiten geothermischer Stromerzeugung in Deutschland, TAB Arbeitsbericht Nr. 84 .

[3] Dipippo, Ronald, Geothermal power plants: Principles, applications, case studies and environmental impact, Elsevier, 2008.

[4] H. Mlcak, An Introduction to the Kalina Cycle, Proceedings of the International Joint Power Generation Conference 30 (1996) 1-11.

[5] S. Ogriseck, Integration of Kalina cycle in a combined heat and power plant, a case study, Applied Thermal Engineering $29(14-15)(2009)$ 2843-2848.

[6] P. Valdimarsson, Factors influencing the economics of the Kalina power cycle and situations of superior performance, Manager (2003) 32-40.

[7] A. Schuster, S. Karellas, E. Kakaras, H. Spliethoff, Energetic and economic investigation of Organic Rankine Cycle applications, Applied thermal engineering 29 (8-9) (2009) 1809-1817.

[8] Dai, Y. and Wang, J. and Gao, L., Parametric optimization and comparative study of organic Rankine cycle (ORC) for low grade waste heat recovery, Energy Conversion and Management 50 (3) (2009) 576-582.

[9] E. Cayer, N. Galanis, H. Nesreddine, Parametric study and optimization of a transcritical power cycle using a low temperature source, Applied Energy 87 (4) (2010) 1349-1357.

[10] M. Kanoglu, Exergy analysis of a dual-level binary geothermal power plant, Geothermics 31 (6) (2002) 709-724.

[11] Z. Gnutek, A. Bryszewska-Mazurek, The thermodynamic analysis of multicycle ORC engine, Energy 26 (12) (2001) 10751082.

[12] F. Heberle, D. Brüggemann, Exergy based fluid selection for a geothermal Organic Rankine Cycle for combined heat and power generation, Applied Thermal Engineering 30 (11-12) (2010) 1326-1332.

[13] P. Mago, L. Chamra, K. Srinivasan, C. Somayaji, An examination of regenerative organic Rankine cycles using dry fluids, Applied thermal engineering 28 (8-9) (2008) 998-1007.

[14] M. Yari, Exergetic analysis of various types of geothermal power plants, Renewable Energy 35 (1) (2010) 112-121.

[15] B. Saleh, G. Koglbauer, M. Wendland, J. Fischer, Working fluids for low-temperature organic Rankine cycles, Energy 32 (7) (2007) 1210-1221.

[16] Borsukiewicz-Gozdur, A. and Nowak, W., Maximising the working fluid flow as a way of increasing power output of geothermal power plant, Applied thermal engineering 27 (11) (2007) 2074-2078.

[17] Nguyen, TQ and Slawnwhite, JD and Boulama, K.G., Power generation from residual industrial heat, Energy Conversion and Management 51 (11) (2010) 2220-2229.

[18] R. DiPippo, Second Law assessment of binary plants generating power from low-temperature geothermal fluids, Geothermics 33 (5) (2004) 565-586

[19] E. Lemmon, M. Huber, M. Mclinden, NIST Reference Fluid Thermodynamic and Transport Properties REFPROP, The National Institute of Standards and Technology (NIST), version 8.0, 2007.

[20] Peterson, P., F2PY: a tool for connecting Fortran and Python programs, International Journal of Computational Science and Engineering 4 (4) (2009) 296-305.

[21] Jones, E. and Oliphant, T. and Peterson, P. and others, SciPy: Open source scientific tools for Python, URL http://www.scipy.org/, 2001-.

[22] Bliem, C.J. and Mines, G.L., Supersaturated Turbine Expansions for Binary Geothermal Power Plants, in: Geothermal Energy and the Utility Market - The Opportunities and Challenges for Expanding Geothermal Energy in a Competitive Supply Market, 105-109, 1992.

[23] Mines, G.L., One year of operation of Mammoth Pacific's MP1-100 turbine with metastable, supersaturated expansions, in: Proceedings Geothermal Program Review XV, vol. 3, Idaho National Engineering and Environmental Laboratory (INEEL), 51-57, 1997. 
[24] Wei, D. and Lu, X. and Lu, Z. and Gu, J., Performance analysis and optimization of organic Rankine cycle (ORC) for waste heat recovery, Energy conversion and Management 48 (4) (2007) 1113-1119. 